\title{
Plasma Enhanced Chemical Vapor Deposition of Organic Polymers
}

\author{
Gerhard Franz
}

Citation: Franz, G. Plasma Enhanced Chemical Vapor Deposition of Organic Polymers. Processes 2021, 9 , 980. https://doi.org/10.3390/ pr9060980

Academic Editor: Monika Wawrzkiewicz

Received: 14 April 2021

Accepted: 9 May 2021

Published: 1 June 2021

Publisher's Note: MDPI stays neutral with regard to jurisdictional claims in published maps and institutional affiliations.

Copyright: (C) 2021 by the author. Licensee MDPI, Basel, Switzerland. This article is an open access article distributed under the terms and conditions of the Creative Commons Attribution (CC BY) license (https:// creativecommons.org/licenses/by/ $4.0 /)$.
Department of Applied Sciences and Mechatronics, Munich University of Applied Sciences (MUAS), 34 Lothstrasse, Munich, D-80335 Bavaria, Germany; gerhard.franz@hm.edu

Abstract: Chemical Vapor Deposition (CVD) with its plasma-enhanced variation (PECVD) is a mighty instrument in the toolbox of surface refinement to cover it with a layer with very even thickness. Remarkable the lateral and vertical conformity which is second to none. Originating from the evaporation of elements, this was soon applied to deposit compound layers by simultaneous evaporation of two or three elemental sources and today, CVD is rather applied for vaporous reactants, whereas the evaporation of solid sources has almost completely shifted to epitaxial processes with even lower deposition rates but growth which is adapted to the crystalline substrate. CVD means first breaking of chemical bonds which is followed by an atomic reorientation. As result, a new compound has been generated. Breaking of bonds requires energy, i.e., heat. Therefore, it was a giant step forward to use plasmas for this rate-limiting step. In most cases, the maximum temperature could be significantly reduced, and eventually, also organic compounds moved into the preparative focus. Even molecules with saturated bonds $\left(\mathrm{CH}_{4}\right)$ were subjected to plasmas-and the result was diamond! In this article, some of these strategies are portrayed. One issue is the variety of reaction paths which can happen in a low-pressure plasma. It can act as a source for deposition and etching which turn out to be two sides of the same medal. Therefore, the view is directed to the reasons for this behavior. The advantages and disadvantages of three of the widest-spread types, namely microwavedriven plasmas and the two types of radio frequency-driven plasmas denoted Capacitively-Coupled Plasmas (CCPs) and Inductively-Coupled Plasmas (ICPs) are described. The view is also directed towards the surface analytics of the deposited layers-a very delicate issue because carbon is the most prominent atom to form multiple bonds and branched polymers which causes multifold reaction paths in almost all cases. Purification of a mixture of volatile compounds is not at all an easy task, but it is impossible for solids. Therefore, the characterization of the film properties is often more orientated towards typical surface properties, e.g., hydrophobicity, or dielectric strength instead of chemical parameters, e.g., certain spectra which characterize the purity (infrared or Raman). Besides diamond and Carbon Nano Tubes, CNTs, one of the polymers which exhibit an almost threadlike character is poly-pxylylene, commercially denoted parylene, which has turned out a film with outstanding properties when compared to other synthetics. Therefore, CVD deposition of parylene is making inroads in several technical fields. Even applications demanding tight requirements on coating quality, like gate dielectrics for semiconductor industry and semi-permeable layers for drug eluting implants in medical science, are coming within its purview. Plasma-enhancement of chemical vapor deposition has opened the window for coatings with remarkable surface qualities. In the case of diamond and CNTs, their purity can be proven by spectroscopic methods. In all the other cases, quantitative measurements of other parameters of bulk or surface parameters, resp., are more appropriate to describe and to evaluate the quality of the coatings.

Keywords: plasma enhanced chemical vapor deposition; organic layers; parylene; diamond-like coatings; carbon nanotubes; superhydrophobicity; functionalization of surfaces 


\section{Introduction}

\subsection{Vapor Deposition Techniques}

The first deposition techniques on molecular level were evaporation techniques. At extremely low vacuum, metals or oxides are evaporated and deposited at colder places of the reactor. The source material (typical are wires or pellets) is located in a boat of inert material, often cooled by water, and heated to enhance the vapor pressure, in most cases up to evaporation point. Metals can be evaporated solely to generate a single-atom film, or as twins to produce an alloy in extremely high purity, often as single crystal. To avoid contamination, the vacuum should reach very low values in the order of $10^{-7}$ Torr. For heating, conventional resistance furnaces can be applied, but also electron beams or lasers. This process is called Physical Vapor Deposition (PVD). Every evaporation process of a metal belongs to this type. These reactions are carried out in a steady-state reactor. At these low vacuum levels, the mean free path (MFP $\lambda$ ) is in the order of some tens of $m$, and that means that no encounter (and hence no reaction) can occur during the flight from source to substrate.

With this technique known as Molecular Beam Epitaxy (MBE), single atomic or molecular layers can be deposited-realizing the electron in a box which had been a gedankenexperiment for more than forty years. The layer is forced to crystallize in the crystal lattice of the subsequent solid. If the layer is identical to the substrate the process is denoted homoepitaxy, otherwise heteroepitaxy. All the layers for optical devices based on III/V semiconductors are fabricated this way. Often, up to four different sources are in simultaneous use. MBE demands even higher vacuum than conventional PVD technique. The standard base level is $10^{-10}$ Torr or even better [1,2].

In fact, atomic sources are used but the result is a chemical compound, different from the reactants, and we have made the first step to Chemical Vapor Deposition (CVD). This technique is characterized by the fact that the evaporated solid is chemically different from the deposited layer. On an atomic or molecular level, chemical bonds have always to be broken in the solid to generate volatile reactive species which deposit later on to form the same or different chemical bonds. The quality of the film mainly depends on the temperature of the substrate, whereas the reaction rate can also be influenced by the vapor pressure of the solid state source (i.e., its temperature according to the equation of Clausius-Clapeyron).

As an example of CVD, the polymerization of parylene (poly-p-xylylen), PPX, is introduced. According to Gorham, PPX is deposited by chemical vapor deposition (CVD) in a two-step process: first, the solid precursor di-parylene $\mathrm{N}(\mathrm{DPX})$ is sublimed at $120-150{ }^{\circ} \mathrm{C}$ and subsequently thermally cracked at typically $700{ }^{\circ} \mathrm{C}$ to the monomer MPX at $700{ }^{\circ} \mathrm{C}$ ( $p$-xylylene radical), which forms polymeric chains of poly- $p$-xylylene (PPX) on cold surfaces or in the vapor [3,4], Equation (1).

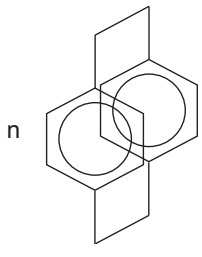

DPX<smiles>Cc1ccc(C)cc1</smiles>

MPX

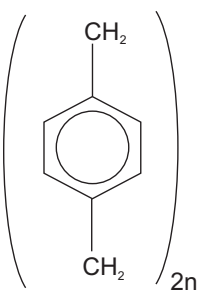

PPX

Soon, it turned out that the vigourous breaking of chemical bonds of a solid could be avoided by introducing a reactive gas, often heated up to enhance its reactivity to an even higher degree. Consider deposits of microcrystalline tungsten which have been evaporated from a glowing wire in an incandescent filament of an Edison light-bulb, thereby thinning the wired and reducing its lifetime. These deposits can be transformed to volatile halogenides of tungsten which are eventually decomposed at the very hot surface of 
the glowing wire, thereby allowing hotter temperatures of the glowing wire and preventing shorter lifetimes of the bulb in one step-a perfect circuit according to Equation (2)

$$
\underbrace{\mathrm{W}+3 \mathrm{Cl}_{2}}_{\text {low temperature }} \rightarrow \mathrm{WCl}_{6} \rightarrow \underbrace{\mathrm{W}+3 \mathrm{Cl}_{2}}_{\text {hot temperature }}
$$

This reaction is a typical example for chemical transport [5], also for the reaction vessel: small charges in a melted glass ampoule which had been evaporated earlier, larger batches in reactors made of steel.

Eventually, applying two vapors as reactants completely avoids the presence of a solid. The development of this branch of CVD began with the decomposition of $\mathrm{SiH}_{4}$ to form polycrystalline silicon, so-called polysilicon, at elevated temperatures and diluted with an inert gas (nitrogen or argon) typically by about a factor of 4 according to the stoichiometric sum reaction

$$
\mathrm{SiH}_{4} \rightarrow \mathrm{Si}+2 \mathrm{H}_{2}
$$

a reaction which requires temperatures between 600 and $6500^{\circ} \mathrm{C}$ and pressures of approx. 50 and 200 mTorr (10 and 150 Pa), so-called Low Pressure Chemical Vapor Deposition, LPCVD.

By oxidation of silane, films of $\mathrm{SiO}_{2}$ can be deposited even at atmospheric pressure (Atmospheric Pressure Chemical Vapor Deposition, APCVD)

$$
\mathrm{SiH}_{4}+\mathrm{O}_{2} \rightarrow \mathrm{SiO}_{2}+2 \mathrm{H}_{2}
$$

applying temperatures beyond $500^{\circ} \mathrm{C}$.

But not only pure compounds are feasible. By adding $\mathrm{PH}_{3}$ or $\mathrm{B}_{2} \mathrm{H}_{6}$ to the ambient $\mathrm{SiH}_{4}$, so-called borophosposilicate glass can be easily produced. The typical reaction takes place in a quartz tube. The wafers are placed vertically on a sledge, drawn in the center of the tube in a zone of homogeneous temperature and are subjected to the hot gases.

The main disadvantage is the very high temperature. The production of $\mathrm{SiO}_{2}$ requires a substrate temperature of at least $500{ }^{\circ} \mathrm{C}$, better more than $750{ }^{\circ} \mathrm{C}$. It is evident that only processing steps at the very beginning of the long series to fabricate a device are possible. The relatively high temperature is not required for cleaving chemical bonds-they are already broken-but it has turned out that the film qualities (poor dielectric strength, conformity) could be improved significantly.

Reactions which use a certain amount of a solid as reactant can be carried out in a steady-state reactor. Steady state reactors exhibit are simple and highly reliable in use. However, they exhibit a principal disadvantage against the flow reactors in mechanistic and preparative terms, respectively. Mechanistically, pressure (and number density) start and end at zero, which causes an even stronger reduction of the reaction rate for a reaction of third order [6]. Preparatively, the number densities of the chain-building monomers and oxygen will become equal, and eventually, the latter will surpass the number density of the monomers. Consequently, the composition and properties of the interfaces will deviate from those of the bulk material. Thus, the vertical homogeneity deteriorates. The last setback can be avoided by stopping the reaction earlier.

In a flow reactor, loss of molecules is caused by the deposition reaction and by the removal of the pumping system. In order to avoid kinetic problems which are common for diffusion-controlled reactions, the deposition must play a secondary role. Otherwise, the flow is likely to change its character, which will cause a series of complications, starting with the temperature and the number density of the monomers. Normally, flow of precursors is easily controlled by mass flow controllers (MFCs).

The main advantage of CVD against the other techniques electron-beam evaporation and sputtering and their derivatives is the conformal deposition even of highly distinct peaks and valleys (Figure 1).

Compared with the other thin-film deposition techniques evaporation and sputtering and their derivatives, the main advantage is the almost perfect conformal coating, equal in 
thickness over the whole three-dimensional landscape of even highly distinct microscopic peaks and valleys. When atoms are set free from the source by the two above-mentioned processes, they will deposit randomly on the cold(er) substrate. In particular for sputtering, the thermal energy of the atoms remains remarkably high which favors hopping processes whereas for deposition, the thermal energy is insufficient even for this process. Hence, an amorphous layer is likely to grow. CVD, however, takes chemistry into account. An open valence of a $\mathrm{Si}$ atom is saturated more effectively by an $\mathrm{O}$ atom than by another $\mathrm{Si}$ atom. The growth rates are high, and even thick layers can be deposited because the mechanical stress is lowermost of all the three deposition techniques-it is very difficult to deposit good-adhering layers beyond $2 \mu \mathrm{m}$ (see Section 2).
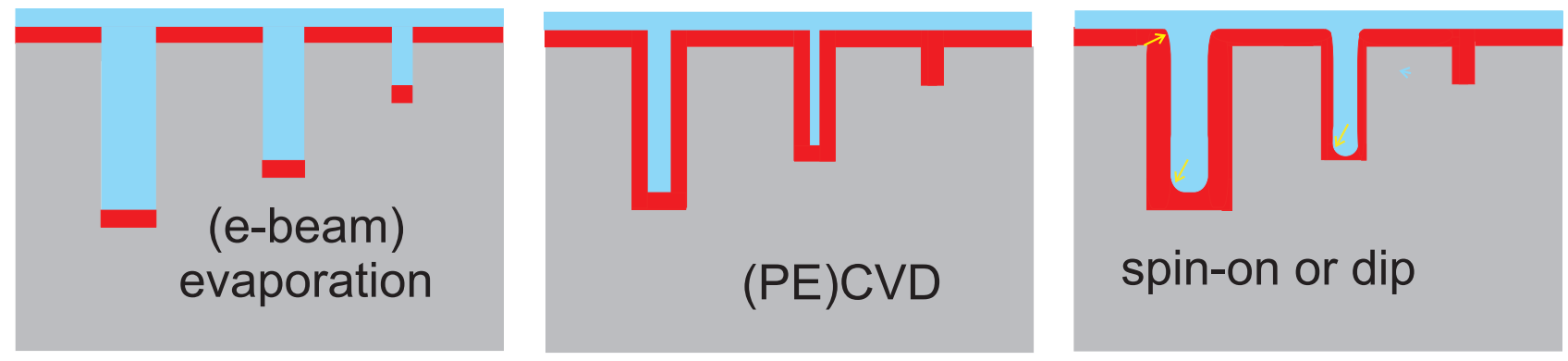

Figure 1. The perfect conformal coating even of very rugged surfaces is second to none for (PE)CVD (middle). Due to the very low pressure which prevents scattering, thereby causing a very directed beam from source to target, techniques as e-beam evaporation or epitaxy cannot coat surfaces which are orientated parallel to the beam (LHS). Dipping or spin-on techniques suffer from the high viscosity and surface tension of the solvent which causes protruding noses and rounded corners (RHS, gray: substrate, red: deposited film, blue: air).

\section{Polymerization in the Volume or at the Surface?}

Chemical vapor deposition differs from physical vapor deposition by the fact that one or more substances are evaporated and undergo a chemical reaction during transport to a surface. According to Equation (1), the polymeric reaction is of radicalic character and happens at two docking positions at the two methylene groups in $p$-position of the benzene ring. This is one of the very rare reactions in organic chemistry with but one reaction track. However, the chain length can vary (molecular weights are typically on the 200,000 to $400,000$ range $[3,7,8])$ and the reaction can occur in the vaporous phase as well as during the process of condensation.

It is evident that low deposition rates are mandatory for a good layer quality. The layerforming atoms or molecules must first condense and react at the right place in a second step. Because deposition is always an exothermic reaction, the generated heat must not heat up the surface uncontrollably. Therefore, the deposition must be steered into the direction of surface polymerization to avoid formation of larger cluster already in the vaporous phase (volume polymerization). This problem was addressed for the first time by Yasuda et al. who diluted the chain-building vapor by an inert gas [9]. They found the expected reduced deposition rate. Additionally, they observed a vertical gradient from the vapor entrance to the pumping flange. According to them, the kinetic energy of the film-building species at substrate level had been reduced by collisions with the atoms of the inert gas [10].

This concurrence between these two competing processes of reactions in the volume and at the surface is a main issue in epitaxy, i.e., crystal-orientated growth. And the leap from simple chemical vapor deposition to advanced epitactic layer formation can be managed only by pushing back reactions in the vaporous phase [11]. This can be easily achieved by dilution of the layer-forming gas(es) with an inert gas. In the case of depositing layers with a certain porosity, the exact control of the growth rate is mandatory and is possible by this epitaxial trick, leading to slowly grown, but high-quality, evenly layers with high a conformity (cf. Section 3) [12]. 


\subsection{Plasma-Assisted Coating Techniques}

Bond breaking results in radicals, i.e., molecular fragments with unpaired electrons. This bond breaking could also be accomplished by a low-pressure athermic plasma. Here, electrons with a thermal energy of some $\mathrm{eV}$ generate all species out of the atomic or molecular source: highly activated molecules, radicals, ions. When these processes were invented and developed, several types of plasmas were commercially available which mainly differed from the evaporation of solid-state sources that they took place in a reactor with continuous flow instead of a steady-state reactor. Typically, the reactor is evacuated by a rotary vane pump down to a pressure in the mTorr range $(0.1 \mathrm{~Pa})$. Permanent gas flow is required to maintain the pressure of operation. For deposition, the amounts of flow are normally measured in liters per minute [Lpm].

The history can be divided into three main streams.

- For transport in the interplanetary space, ion thrusters had been developed after the sputnik shock in the late 1950s. As spin-off, the first ion beam systems appeared, operated with a Kaufman-type plasma source and inert gases as $\mathrm{Ar}, \mathrm{N}_{2}$, and $\mathrm{O}_{2}$ in a pressure range below $1 \mathrm{mTorr}$ [13]. Ions of these gases were directed to dielectric or metallic targets which caused sputtering. The removed species could be deposited on substrates in various compositions.

- As spin-off of RADAR, microwave-driven (MW) reactors were invented which operated in the optimum range of some Torrs (some hundreds of $\mathrm{Pa}$ ). In the high-frequency regime of some $\mathrm{GHz}$ - the FCC frequency of $2.45 \mathrm{GHz}$ was fixed in the late 1940s-the optimum pressure is some Torrs (for effectiveness of power transfer, the frequency of elastic collision should match the operating frequency [14]).

- In the 1960s, also the RF range came into focus. Parallel-plate reactors were operated at the FCC frequency of $13.56 \mathrm{MHz}$ at pressures of some tens of mTorr. The first layers were deposited on lenses of silica for dielectric coating, by adding the two reactive gases $\mathrm{SiH}_{4}$ and $\mathrm{NH}_{3}$ or $\mathrm{N}_{2} \mathrm{O}$ in traces to an inert carrier gas. The sample was placed on the "cold" electrode, i.e., the electrode which was opposed that electrode which was driven with the HF voltage. This caused a small voltage drop in front of the sample across the RF sheath of approx. 10-20 V from plasma potential to ground. This was the birth of real chemical vapor deposition with plasma triggering, which was coined later as Plasma-Enhanced Chemical Vapor Deposition (PECVD). The excitation mode was denoted capacitive coupling [14], abbreviated CCP for Capacitively Coupled Plasma.

In contrast to "simple" vapor deposition, a lot of additional parameters can be used to influence the properties of the deposited film. Among them are RF power and the discharge pressure which determine the two plasma parameters plasma density $n_{\mathrm{P}}$ [in fact, in electropositive plasmas as argon or oxygen at low pressures below $100 \mathrm{mTorr}(15 \mathrm{~Pa})$ the electron density $n_{\mathrm{e}}$ equals the plasma density $\left.n_{\mathrm{P}}\right]$ and electron temperature $T_{\mathrm{e}}$. According to the zero-dimensional Global Model, $n_{\mathrm{P}}$ scales with power input, and $\ln T_{\mathrm{e}}$ scales inversely with pressure [15].

As an example, $\mathrm{SiO}_{2}$ is deposited by the surface reaction of silane and nitric oxide according to the stoichiometric sum reaction

$$
\mathrm{SiH}_{4}+2 \mathrm{~N}_{2} \mathrm{O} \longrightarrow \mathrm{SiO}_{2}+2 \mathrm{H}_{2}+\mathrm{N}_{2} .
$$

In contrast to CVD, this reaction can be carried out at only $300^{\circ} \mathrm{C}$ - compared with 500-600 ${ }^{\circ} \mathrm{C}$ in conventional CVD. But also other molecules can be decomposed to form $\mathrm{SiO}_{2}$. Typical reactions are the decomposition of tetraethylorthosilicate (TEOS) according to Equation (6) (Et means $\mathrm{C}_{2} \mathrm{H}_{5}$ )

$$
\mathrm{Si}(\mathrm{OEt})_{4}+\mathrm{O}_{2} \longrightarrow \mathrm{SiO}_{2}+\text { products }
$$

or of hexamethyl disiloxane, HMDSO, according to Equation (7) (Me stands for $\mathrm{CH}_{3}$ )

$$
\mathrm{Me}_{3} \mathrm{Si}-\mathrm{O}-\mathrm{SiMe}_{3}+\mathrm{O}_{2} \longrightarrow \mathrm{SiO}_{2}+\text { products. }
$$


These reactions can be carried out at slightly enhanced temperature because the vapor is admitted into the reactor by a heated gas pipe $\left(39-56{ }^{\circ} \mathrm{C}\right)$ [16]. Oxygen in excess serves to combust the waste carbon. For some considerations with respect to the reaction mechanism, cf. Section 2.2.

We see: plasma enhancement augured a dramatic lowering of the processing temperature. The highest temperature for decomposing $\mathrm{SiH}_{4}$, as it turned out, was only $300{ }^{\circ} \mathrm{C}$, in the more recent variant, the inductively coupled plasma, $120^{\circ} \mathrm{C}$ or even less are sufficient. The larger diameter of the reactor allowed wafer processing of up to 12 " in diameter. And for other precursors, we had reached room temperature.

In all these cases [Equations (5)-(7)], inorganic compounds are considered. The interaction of the hot electrons with the reactants results in a cleavage of one or two or all bonds within the molecule and a formation with new partners which generates an inorganic polymer, i.e., a three-dimensional giant molecule. But what happens to the organic groups (Me or Et)? It is well-known that chain-formation Me and Et terminates at the first step yielding Me-Me or Et-Et, resp. This issue is well-known from scanning electron microscopy. The electron beam generates carbonaceous traces on the inspected surface by decomposing pump oil. As significant result from this observation, the conclusion must be drawn that the electronic attack on molecules can lead to various consequences.

\subsection{Plasma-Assisted Etching Techniques}

Simultaneously, processes were developed to remove layers by exposing them to plasmas. Targeted removal began in ion beam systems in the early 1960s at very low pressures (below 1 mTorr). The plasma sources were of the Kaufman type operated at DC. In today's nomenclature, this would be denoted Chemically-Assisted Ion Beam Etching (CAIBE). From the high pressure front (approx. 1 Torr, i.e., three orders of magnitude higher), oxygen was used in microwave-driven discharges to remove photoresist. The first etching processes in parallel-plate reactors at $13.56 \mathrm{MHz}$ were developed to etch silicon and silica. It was well-known that both materials could be etched by fluorine-containing molecules, e.g., $\mathrm{CF}_{4}$ or $\mathrm{SF}_{6}$. In contrast to the parallel-plate reactors which were used for deposition, the sample which was to be etched was placed atop the so-called "hot" electrode. Here, the voltage drop across could easily reach some hundreds of V. To the voltage drop from plasma potential to ground, the so-called "DC-bias" voltage had to be added. This caused a significant anisotropy of etching. For directions parallel to the electric field, the etch rate could increase steeply and could pass the horizontal etch rate by a factor of up to 100. This feature dominated the process and was therefore coined Reactive Ion Etching, RIE. In contrast to a typical PECVD reactor, an RIE reactor is equipped with a dual pumping system consisting of a turbopump which is evacuated by a conventional pump, often a rotary vane pump. This system reaches a typical base vacuum of better than $10^{-6}$ Torr, i.e., three orders of magnitude below the residual vacuum in a PECVD reactor. The amounts of flow are measured in standard cubic centimeter per minute [sccm].

\subsection{PECVD vs. RIE}

These two techniques, although carried out in the same reactors but at different experimental conditions were shown to be two sides of the same coin by a revolutionary experiment which had been performed by the famous researcher duo John W. Coburn and Harold F. Winters in 1979. They clearly showed that the same molecules, namely the row $\mathrm{CF}_{4}, \mathrm{CHF}_{3}, \mathrm{CH}_{2} \mathrm{~F}_{2}, \mathrm{CH}_{3} \mathrm{~F}, \mathrm{CH}_{4}$ could either act as an etchant or as a film-building species, in the case of etching

$$
\mathrm{SiO}_{2}+2 \mathrm{CH}_{2} \mathrm{~F}_{2} \rightarrow \mathrm{SiF}_{4} \uparrow+\text { products }
$$

forming volatile $\mathrm{SiF}_{4}$, and in the case of deposition

$$
\mathrm{n} \mathrm{CH}_{2} \mathrm{~F}_{2} \rightarrow\left(\mathrm{CF}_{2}\right)_{\infty}+\text { products, }
$$


forming perfluorated polymers (teflon). $\mathrm{CF}_{4}$ is a pure etchant in reactors equipped with electrodes made of quartz, irrespective of whether it is employed in microwave-driven barrel reactors or in parallel-plate reactors at $13.56 \mathrm{MHz}$, whereas $\mathrm{CHF}_{3}$ is an etchant only in the latter. $\mathrm{CH}_{2} \mathrm{~F}_{2}$ polymerizes in both types as well as the unsaturated compound $\mathrm{C}_{2} \mathrm{~F}_{4}$. In contrast, for the latter, ion bombardment enhances the rate of polymerization (Figure 2). This conduct may be attributed to the influence on the rate-limiting step which has turned out to be the formation of reactive intermediates which are chemisorbed by surface sites.

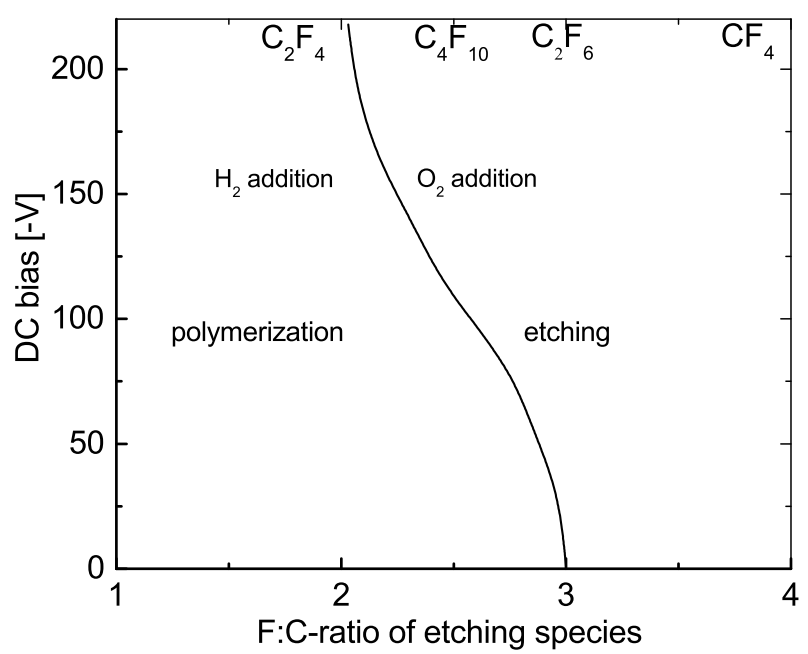

Figure 2. Schematic diagram of the influence of the ratio between $\mathrm{F}$ and $\mathrm{C}$ in the reactive gas and the DC bias voltage on the reaction behavior on the substrate. Enlarged loading as well as addition of hydrogen favors the formation of a polymeric film [17] (@ IBM).

Coburn and Winters showed by experiment that the qualitative dependence of the reactive behavior (either etching or depositing) is caused by the ratio between carbon and fluorine which must be less than $1 / 2$ to ensure etching, which is synonymous with avoiding $\mathrm{CF}_{2}$ becoming the dominant species in the discharge which causes deposition of a fluorocarbon film [18].

This turning point between etching and coating is denoted polymer point; the point itself and its dependence on typical process parameters is extremely important to establish and stabilize a technological process.

The didactic brilliance of this experiment is owed to its straightforward chemical (self-)explanation, turning changes of quantity into changes of quality. Now, also the different conduct of the same etchant acting on different electrode materials can be readily explained: In a discharge through pure $\mathrm{CF}_{4}$, at a grounded electrode made of silica an etching process takes place, whereas under the same conditions, an electrode made of silicon causes the deposition of a polymeric film. Since in either reaction fluorine is consumed, the ratio between carbon and fluorine will rise in the atmosphere. This increase is at least partly compensated by the etching of silicon dioxide. The oxygen which is set free is removed from the equilibrium by forming volatile carbon oxides.

\subsection{Disadvantages and Advantages of Plasma Processing}

For preparative purposes, the parallel-plate reactor dominated the market in the 1970s and 1980s. Processes could be influenced by the plasma parameters RF power, discharge pressure, gas composition, dilution of the reactive gases over a vast range. One of the most prominent features was the almost perfect conformity of the coatings. One of the most severe setbacks was the still high processing temperature. Another major setback in plasma processing was the impossibility of steering the growth rate or etch rate independently from application of the DC bias voltage. That meant for plasma deposition: increasing the power input caused higher negative voltages at the hot electrode opposing the wafer which caused sputtering of the electrode leading to contamination at the substrate electrode. 
For etching, that caused severe damage: physical or crystal damage, chemical damage by forming unintended bonds and compounds.

These items were addressed by the next generation of plasma reactors, which generate plasmas in an inductive way [19].

In Figure 3, RF-driven reactors are displayed, 1 being a conventional parallel-plate reactor. The substrate is placed on the grounded electrode. In this figure, the grounded electrode is replaced by an RF-driven electrode which has a great benefit for influencing the mechanical stress of the deposited films. Opposed to that electrode, the gas shower head is mounted. The small holes are drilled into the plate in three of four concentric rings which act as jets to optimize the gas distribution. RF power is transmitted via the gas shower head into the plasma between the two "electrodes".

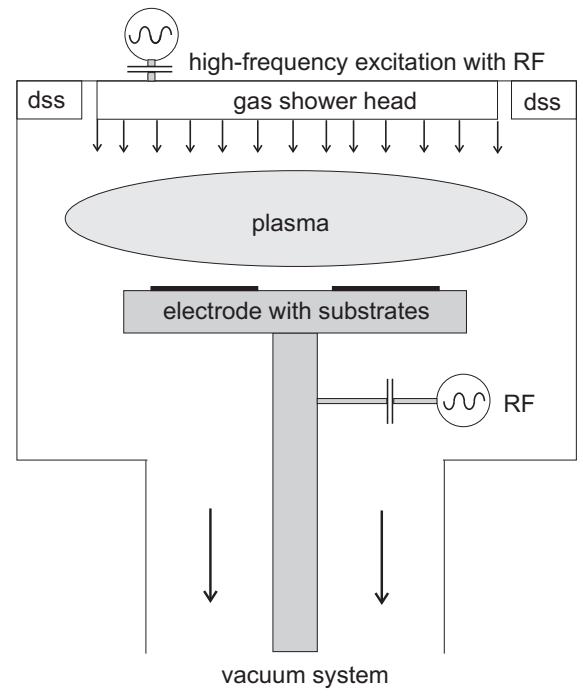

(1)

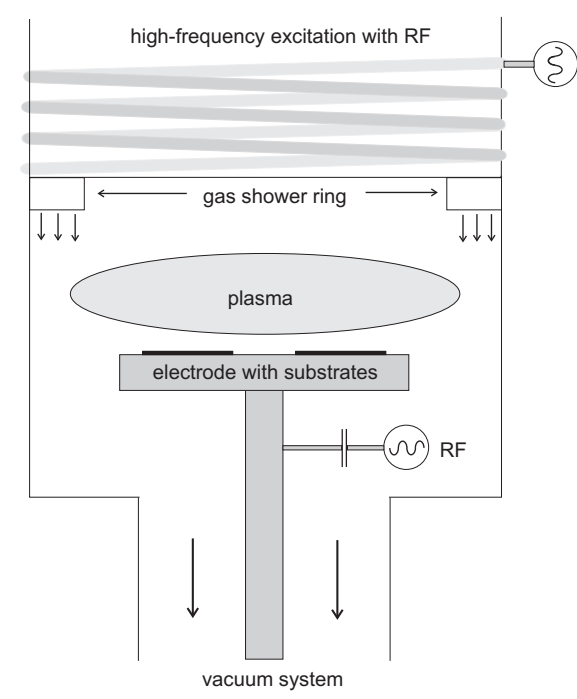

(2)

Figure 3. PECVD reactors. (1): parallel-plate reactor with inverted power configuration. The substrate is placed upon the "cold" electrode, which is normally grounded. The capacitive coupling offers the possibility of substrate biasing for stress control. (2): ICP reactor with capacitively-coupled bottom electrode. Operating frequencies for plasma generation are 13.56/27.12 MHz; for bias, 2 or $13.56 \mathrm{MHz}$ are customary, sometimes frequencies in the high $\mathrm{kHz}$ range. "dss" denotes the dark space shield which suppresses sputtering of the shower head. A conventional parallel-plate reactor for PECVD is evacuated by a one stage pump system which reaches a vacuum of 1 mTorr, whereas an ICP reactor is always evacuated by a double pump system (in most cases the second stage is a turbopump), and the base vacuum is better than $10^{-5}$ Torr $(<1 \mathrm{mPa})$.

In an ICP reactor, the gas shower head is replaced by the plasma source and a ring with jets (2; in Figure 11, an example of an MW-driven reactor is depicted).

In terms of the degree of ionization, i.e., the ratio of ionized particles to all particles, the three excitation methods differ by three orders of magnitude, starting by $10 \mathrm{ppm}$ in MW discharges, next in line are the CCPs with $0.1-1 \%$, being topped by ICPs which exhibit a plasma density larger than $1 \%$ for typical excitation conditions. Because the pressure in microwave discharges exceeds the pressure in the other two systems by a factor of typical 50 to 100 (some mTorr in ICPs, some tens of mTorr in CCPs, some Torr in MW plasmas), the plasma density in MW Plasmas and ICPs is nearly the same (typical $10^{11} \mathrm{~cm}^{-3}$ ), whereas in CCPs, it is lower by one order of magnitude. In fact, the measured plasma density is the electron density $n_{\mathrm{p}}$, because electrons are measured by Langmuir probes or microwave reflection probes; only in electronegative plasmas as in discharges through $\mathrm{SF}_{6}$, there exists a large part of negatively charged ions [20].

In contrast to the plasma density, the electron temperature is lowest in ICPs. For the other discharges, the simple term electron temperature is questionable. Briefly, this is due 
to the lower plasma density which prevents numerous collisions between electrons by which the electron energy distribution function is shifted towards Maxwellian behavior. But only in ensembles whose energy distribution follows Maxwell, the temperature is well defined. Therefore, in CCPs the distribution often follows the Dryvesteynian behavior.

To summerize, the excitation of species by electron impact is most effective in ICPs, followed by the capacitively-coupled mode, the lowest efficiency is observed in MW discharges-but these are definitely the cheapest discharges.

Since all these techniques require vacuum, at least three orders of magnitude in the case of MW plasmas and even two to three orders lower for RF plasmas, they belong to low-pressure techniques, and are abbreviated LP-PECVD. After turn of the century, also atmospheric plasmas gained permanently increasing interest, so-called AP-PECVD. With their help, surfaces can be modified which cannot be exposed to low pressures. One of these spectacular examples is the hydrophilization of surfaces of polypropylene which were described and modeled by Dorai and Kushner in 2003 [21].

In this article, we confine to LP-PECVD, and we begin the next chapter with a detailed look on the term "ion etching".

\section{Mechanisms}

\subsection{What Causes Ion Etching in Reality?}

We first focus on the etch process which has been investigated in all aspects: the etching of silicon with $\mathrm{CF}_{4}$ by which the volatile $\mathrm{SiF}_{4}$ is generated:

$$
\mathrm{Si}+\mathrm{CF}_{4} \longrightarrow \mathrm{C}+\mathrm{SiF}_{4}
$$

Example 1. For a typical plasma density of a capacitively coupled plasma of $10^{10} / \mathrm{cm}^{3}$ (this term addresses the electron density), we can calculate an ion flux of $10^{15} / \mathrm{cm}^{2}$ s (for example a plasma with an electron temperature $T_{\mathrm{e}}$ of $3.5 \mathrm{eV}$, a plasma density $n_{\mathrm{p}}$ of $1 \times 10^{10} \mathrm{~cm}^{-3}$, and an ion flux of $\Gamma_{\mathrm{i}}$ of $\left.2 \times 10^{15} / \mathrm{cm}^{2} \mathrm{~s}\right)$. These conditions trigger at medium etchrates of $100 \mathrm{~nm} / \mathrm{min}(16.7 \AA / \mathrm{s})$ a flux of volatile $\mathrm{SiF}_{4}$ which is ten times the calculated value, and it would mean that the ratio of removed silicon atoms to incident ions would be about 3, and the number of required halogen atoms would be about 10: Even if all ion attacks are assumed to be successful, medium etchrates cannot be explained. This dilemma can be avoided only with the assumption of the presence of neutrals, mainly radicals, in the kinetic equations.

In fact, it turned out that the term RIE was wrong what the number of ions is concerned but it was right in describing their influence in the etching process. Despite their small number, ions are responsible for the anisotropy and for the enhancement of the reaction rate. The rate-limiting step is mainly the generation of a free atomic site by an ion which can be attacked afterwards by a reactive species. In a parallel-plate reactor, a capacitively-coupled plasma mainly generates radicals and other activated species, but ions only to a lesser content (not higher than $10^{10} / \mathrm{cm}^{3}$ ). Therefore, etching in parallel-plate reactors should be denoted better as ion-assisted chemical etching. Real RIE can be performed in high-density plasmas (inductively-coupled or excited by electron cyclotron resonance in the microwave region or helicon wave excited in the RF region with a plasma degree in the percent region or even higher).

\subsection{What Causes Plasma-Enhanced Chemical Vapor Deposition in Reality? \\ 2.2.1. Growth Rate}

Hence, the plasma effectively influences both the sides of the process, namely generation of the reactive species and the influence at the interface solid-plasma, in the case of deposition the bond formation. As has been outlined in Section 2.1, radicals are the main reactive species in a capacitively-coupled plasma. For generating bonds, similar charges of the fragments would indeed hamper bond formation [consider sol-gel processes with large clusters consisting of some thousands of atoms with equal charges which prevent deposition (purple of Cassius)]. And in vacuum, a heterolytic cleavage of a bond with 
generation of plasmas is energetically highly unfavorable. For example, the dissolution of a salt by water is only possible because the Coulombic attraction between the two charges is reduced by water with its extremely high dielectric constant.

After having been generated, radicals form bonds without almost no activation energy. It is more a matter of migration at the surface to find the correct site-easy for metals and ionic lattices, difficult for long-chain polymers which can grow only at their ends.

Therefore, the rate-limiting step of this process is the generation of active species. If $\mathrm{M}$ denotes a radicalic fragment of the mother molecule $\mathrm{MM}, \mathrm{e}_{0}^{-}$an electron, the principal stoichiometric reaction for heterolytic dissociation reads

$$
\mathrm{MM}+\mathrm{e}_{0}^{-} \longrightarrow \mathrm{M} \cdot+\mathrm{M}^{-},
$$

and considering that

- the equality of the density of the two products $\mathrm{M}^{-}$and $\mathrm{M} \cdot\left(n_{\mathrm{M}^{-}}=n_{\mathrm{M}}\right)$, and that

- $n_{\mathrm{MM}}$ scales with the partial pressure of MM $p_{\mathrm{MM}}$

the law of mass action together with the Gibbs-Helmholtz relation $\left(\Delta G^{0}=-R T \ln K\right.$, with $\Delta G^{0}$ Gibbs's free energy at standard conditions, $R$ the gas constant, $T$ the absoulte temperature, and $K$ the equilibrium constant) can be written as in

$$
n_{\mathrm{M} \cdot}=\sqrt{n_{\mathrm{e}} n_{\mathrm{MM}}} \mathrm{e}^{-\frac{\Delta G^{0}}{k_{\mathrm{B}} T}}
$$

The density of the reactive radicals $n_{\mathrm{M}}$. scales with the partial pressure (or density) of the reactant $n_{\mathrm{MM}}$ and the electron density $n_{\mathrm{e}}$ which equals the plasma density $n_{\mathrm{P}}$ in electropositive gases like $\mathrm{Ar}$, and even $\mathrm{N}_{2}$ and $\mathrm{O}_{2}$ at pressures below 1 Torr $(133 \mathrm{~Pa})$. $n_{\mathrm{P}}$ scales with effective power input [15].

Because $T_{\mathrm{e}}$ scales inversely with the logarithm of total pressure $\left(n_{\mathrm{P}} \propto \ln p\right)$ increasing partial pressure of the reactant does not necessarily cause a higher density of radicals. Experimentally, the density of radicals is found to increase with rising partial pressure up to a certain amount, will saturate and eventually decrease due to dropping electron temperature.

At low plasma power, the power is not sufficient to complete bond-breaking. Therefore, the number density of radicals increases with rising power (energy-deficient region). This effect saturates at a certain threshold which was denoted "critical composite parameter" by Yasuda and Hirotsu [22]. Despite the offering of more power, no further activation can occur. If the power input is increased even further, a complete destruction of the mother molecules can or will occur leading to dropping densities of the reactive species. This regime is denoted passivation, and the principal dependence is sketched in Figure 4.

The density of radicals exhibits a maximum with respect to the total pressure and the absorbed power.

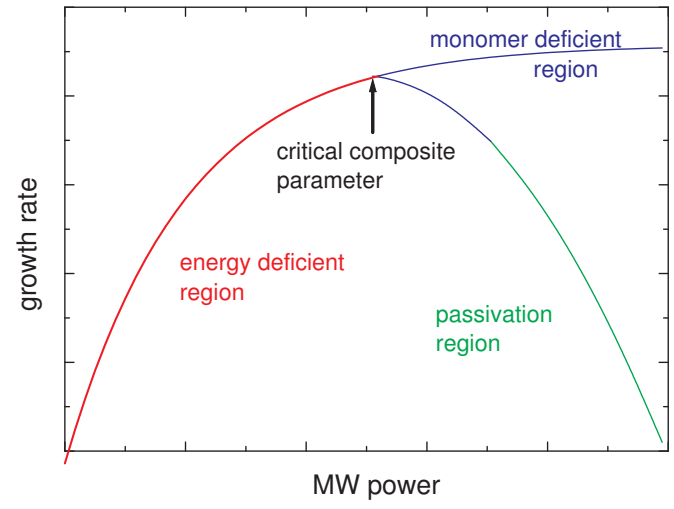

Figure 4. Schematic diagram of the growth rate as function of power input of a mother molecule $\mathrm{M}_{2}$ which is going to be dissociated by a bimolecular plasma reaction after Yasuda and Hirotsu [22,23]. 


\subsubsection{Fragmentation in the Plasma}

For inorganic polymers, e.g., $\mathrm{Si}$ or $\mathrm{SiO}_{2}$, the constituents of the lattice are atoms or smallest fragments which are generated in the gas phase thermally or by electron impact. They condense and form the three-dimensional polymer. In the case of the aforementioned decomposition of prototypic TEOS or HMDSO, a sufficient quantity of oxygen is required to prevent the incorporation of carbon-containing species as Me or methylene groups, $: \mathrm{CH}_{2}$. The deposition results in a microcrystal or in an amorphic glass which are well defined. Even the smallest microcrystals can have identical properties of larger units.

The issues of PECVD of inorganic layers are mainly purity which can be investigated by surface analytics [e.g., secondary ion mass spectrometry (SIMS), Auger electron spectroscopy (AES), wavelength- or energy-dispersive X-ray electron beam analysis (XDX or EDX)] or by physical methods which define also the properties (refraction index, electrical conductivity, ...). A significant branch is devoted to the influence of layer growth and growth conditions on the properties of the deposited layer. The growth process does not result in a large single crystal which is caused by unnumbered influences. Even the resulting microcrystallites exhibit dislocations and they are mutually separated by voids. The resulting layer shows tensile or compressive stress which can be measured by wafer bending $[24,25]$. The resulting porosity results in a reduced density which can be effectively tackled by application of a substrate bias [26].

For organic polymers, both parts are subjected to investigations. What happens in the gas (vaporous) phase, and how will the fragments form a polymer?

It is a simple chemical question whether polymerization can occur in ethylene or in ethane. The answer is: it is easily possible in ethylene but it is forbidden in ethane. It is evident that Me groups cannot form chains. But what will happen if ethane $\left(\mathrm{C}_{2} \mathrm{H}_{6}\right.$ or $\mathrm{Me}_{2}$ ) is subjected to plasma interactions? Organic polymers do not form crystals with well-defined properties. Therefore, the accuracy of the published properties are scattered more broadly. For example, the refraction index of most polymers is accurate to but two decimal places, whereas for "normal" organic compounds, four decimal places are common. The reason for that deviating behavior is twofold:

- $\quad \mathrm{a}$ atom is able to form bonds to other $\mathrm{C}$ atoms, and

- the length of the resulting polymers is not fixed but scatters around a certain average. The degree of this distribution is denoted dispersity. Even when only one type of chain is formed, the length cannot be fixed to a sharp value. In principle, the chain length can be steered by a catalyst which is simply impossible for a heterogeneous reaction which is discussed here (see the discussion which was started at ETH in Zurich [27]).

To focus on these issues, the first question is: what are the species which are generated in the plasma and will form the deposit?

The key experiment was performed by Jensen et al. in 1983, who analyzed the polymerization of ethane in a flow parallel-plate reactor, driven at $13.56 \mathrm{MHz}$ with a base pressure of 20 mTorr. They could detect large amounts of $\mathrm{C}_{3} \mathrm{H}_{8}$, followed by $\mathrm{C}_{2} \mathrm{H}_{4}$ and $\mathrm{CH}_{4}$ by gas chromatography $\left.[28,29]\right)$. This clearly indicates the plasma-induced abstraction of hydrogen from $\mathrm{C}_{2} \mathrm{H}_{6}=\mathrm{Me}_{2}$ as first step

$$
\mathrm{Me}_{2}+\mathrm{e}_{0}^{-} \longrightarrow \mathrm{Et} \cdot+\mathrm{H} \cdot
$$

which is followed by other stripping reactions, e.g.,

$$
\mathrm{Me}-\mathrm{CH}_{2} \cdot+\mathrm{e}_{0}^{-} \longrightarrow \mathrm{C}_{2} \mathrm{H}_{4} \ldots
$$

But these highly reactive groups exhibit a double radicalic function which allows formation of derivates with a number of $C$ atoms higher than two. The formation of linearly chained, but also branched molecules can happen as e.g.,

$$
\mathrm{C}_{2} \mathrm{H}_{4}+\mathrm{CH}_{4} \rightarrow \mathrm{C}_{3} \mathrm{H}_{8} \rightarrow \mathrm{C}_{3} \mathrm{H}_{6} \ldots
$$




$$
\mathrm{C}_{3} \mathrm{H}_{6}+\mathrm{CH}_{4} \rightarrow \mathrm{Me}_{3} \mathrm{C} \cdot+\mathrm{H} \ldots
$$

The growth rate as function of gas flow and constant power input can then be described by a steep increase (energy-deficient region) which does not saturate but drops down due to the shorter residence time of the reactive species. This eventually lead to the formation of deposits which can be weighed (Figure 5).

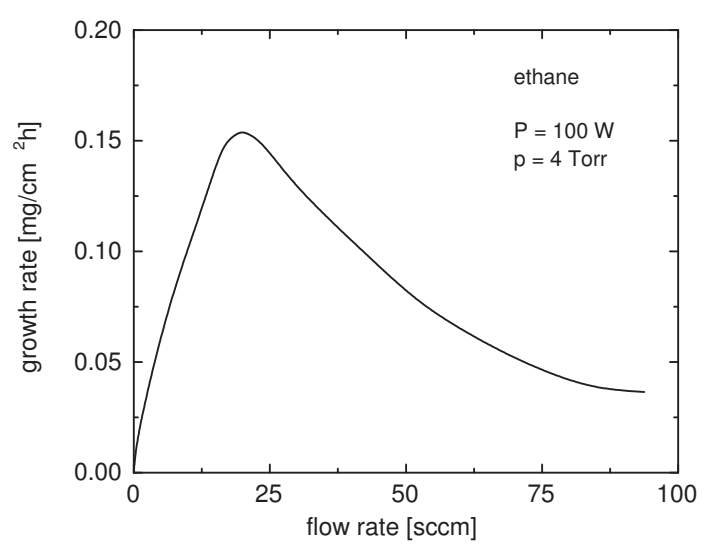

Figure 5. Schematic diagram of the growth rate of a polymer which is deposited when ethane is subjected to an RF discharge after Jensen et al. Shown the growth rate (weight gain per hour) as function of the flow rate of ethane at constant plasma conditions [28,29].

\subsubsection{Diamonds and Diamond-Like Coatings}

In organic layers, especially these : $\mathrm{CH}_{2}$ groups [in general : $\mathrm{CR}_{2}$ with $\mathrm{R}$ an organic group, e.g., an aliphatic (Me, Et) or aromatic $\left.\left(\mathrm{C}_{4} \mathrm{H}_{5}\right)\right]$ are the film-building groups. The result

is a one-dimensional chain of methylene groups. If a $\vdots \mathrm{CH}$ group is incorporated, a branched two- or three-dimensional structure is being formed. The C-C binding energy is far lower than the comparable energy in inorganic compounds, especially in oxides. As final result of the stripping process, all the hydrogen atoms have disappeared, and four bonds to adjacent carbon atoms are formed. As a visible result, a nano diamond has been formed. Myriads of these units with a contaminated surface form Diamond Like Coatings (DLC) which can confluence to form a larger diamond crystal.

Whereas the first experiments have been performed in ion beam reactors by Aisenberg and Chabot in 1971 [30], the group around Derjaguin was successful in CVD reactors (1981) [31]. In the West, these fundamental observations and investigations were only paid scornful attention, since the very same Derjaguin brought the discovery of polywater before the scientific public five years earlier, a new modification of $\mathrm{H}_{2} \mathrm{O}$ which simply turned out to be sweat of russian scientists.

It is evident that the formation of DLCs is a stage finish on the challenging end to pick macroscopic crystals of diamond out of the PECVD reactor. But even the DLCs exhibit various properties of real diamonds like extreme hardness-and they are much cheaper to obtain!

Although best results with respect of purity are expected in hydrocarbons with high an amount of tertiary $\mathrm{C}$ atoms (as in $\left(\mathrm{CH}_{3}\right)_{3} \mathrm{C}$ ), simple discharges through methane with hydrogen yielded the best results. As Bachmann has pointed out, atomic hydrogen could react with a terminal hydrogen to molecular hydrogen, thereby generating an active site which would facilitate the docking of another active carbon atom [32]. A good example to confirm this assumption is displayed in Figure 6, a result which has been obtained in an inductively coupled plasma (ICP) [33].

In these experiments performed by Awakowicz, it is merely a discharge through hydrogen than through methane-with remarkable results.

Therefore, a simple hydrocarbon structure which is built of just primary carbon atoms (in the case of methane, just one carbon atome with four heteroatoms) forming a $\mathrm{CH}_{2}$ chain 
with two terminal $\mathrm{CH}_{3}$ groups will end also with secondary $\mathrm{C}_{2} \mathrm{CH}$ and even tertiary $\mathrm{C}_{3} \mathrm{C}$ atoms. With heteroatoms in the initial compound, the variety of possible reactions will grow explosively-as it well-known to every organic chemist.

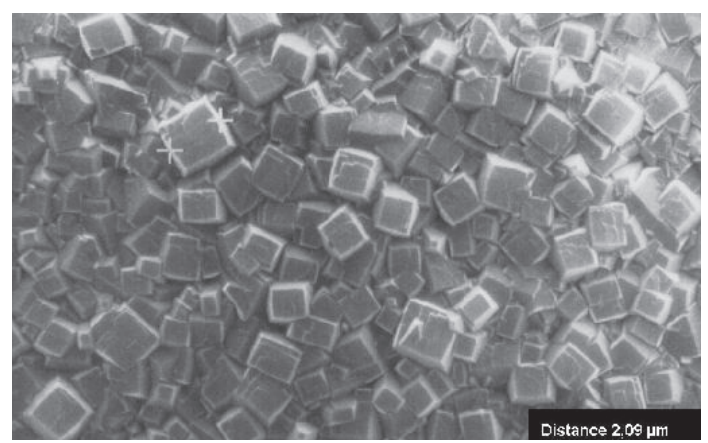

Figure 6. Polycrystalline layer of cubic crystals of diamond, deposited in an ICP reactor at 3 Torr and RF power input of $1200 \mathrm{~W}, \mathrm{Ar}: \mathrm{H}_{2}: \mathrm{CH}_{4}=250: 25: 0.5 \mathrm{sccm}$. The bar represents 2.09 $\mu \mathrm{m}$ [33] (with kind permission from Peter Awakowicz, 2021).

\subsubsection{Carbon Nano Tubes}

In the 1980es, the hollow molecule $\mathrm{C}_{60}$ draw attention, a molecule which consists of twelve pentagons and twenty hexagons which exactly the same configuration as those footballs which were used in the top soccer leagues across Europe. Since Kepler's Gedankenexperiment, the impossibility to parquet a two-dimensional plane without any gap is well-known. But to fill the gap, some hexagons are required. Additionally, a curvature into the third dimension is required (Figure 7).

In the first recipes, graphite has been evaporated in a low-pressure arc (in fact: PECVD!) and was analyzed spectroscopically by means of IR [34].

All the carbon atoms are $s p^{2}$ hybridized. According to Hückel, to meet the quality of aromatizity, all the atoms must be $s p^{2}$ hybridized $(\sqrt{ })$, and the structure must not be uneven $(\times)$. However, the curvature between adjacent atoms is still very low.

In 1991, Carbon NanoTubes (CNTs) were discovered by Iijima [35] which were extensively investigated since then (see e.g., [36,37]): tubes of carbon which is $s p^{2}$ hybridizedas in graphite or benzene. In its typical characteristics, it consists either of a single wall (SW-CNT) or a wall consisting of only some layers (MW-CNT) of condensed benzene cores, wound around an imaginary thread with a diameter of just but some nanometers (Figure 8.1). The imaginary thread exhibits a length of $\infty$ (often some $\mathrm{cm}$ ) and is chaotically orientated. It is PECVD that allows the simultaneous growth of thousands of parallel-orientated trees, as in Figure 8.2A.

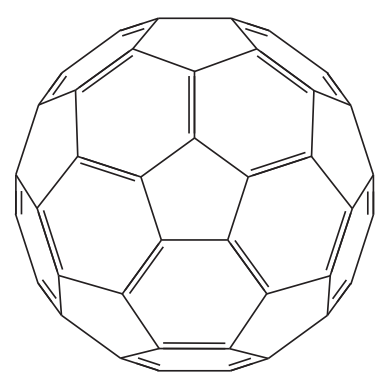

Figure 7. An allotropic form of carbon, the molecule (Buckminster-)fullerene, $\mathrm{C}_{60}$, consisting of twelve pentagons and twenty hexagons shaped into three-dimensional space. 


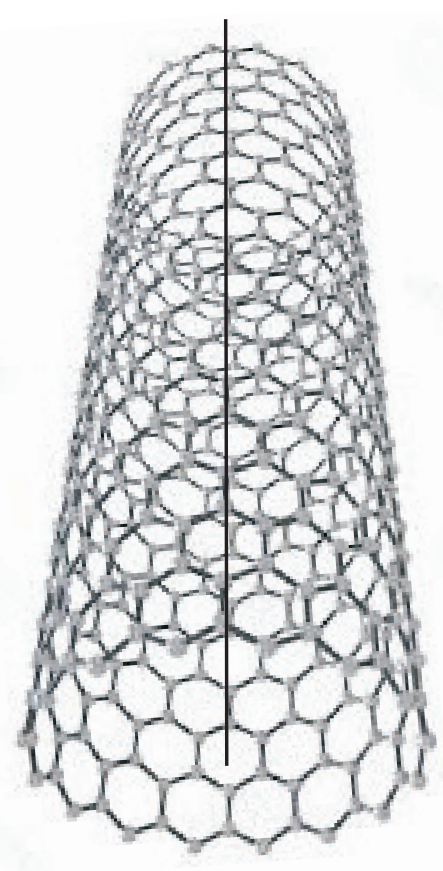

(1)

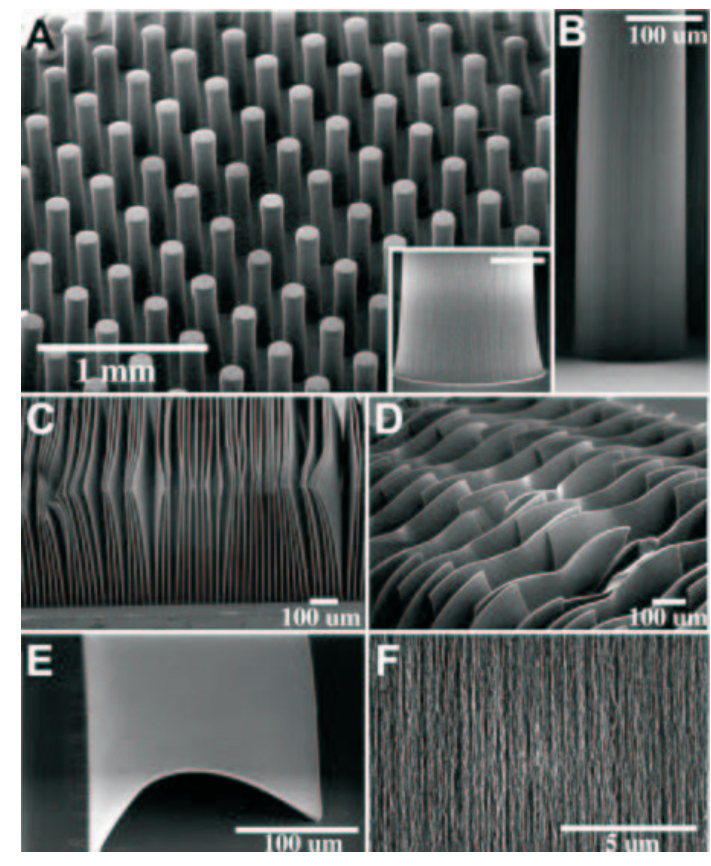

(2)

Figure 8. (1): Principal sketch of a single-wall carbon nanotube (SWCNT). (2): SEM micrographs of organized SWCNTs: (2)/(A): nanotube forest with anisotropic growth, (2)/(B): very smooth surface of the trees; (2)/(C,D): the leaves prove: no steric obstacles during growth; (2)/(E): a single leaf; (2)/(F): surface of a leaf [37] (with kind permission from Science, 2021).

\subsubsection{Analysis of the Deposited Layers}

Whereas it is easy to measure the gaseous components using mass spectrometry or chromatography, it is extremely difficult to analyze the deposited films. This discussion has been fueled since the successful preparations of pure crystals of diamond [30,31] (Figure 6) which are significantly paced forward in Augsburg/Germany by the Schreck group to get the transition done from numerous small crystals to one large single crystal [38,39] and, later on, when CNTs absorbed the interest of many researchers.

For plasma deposition of $\mathrm{SiO}_{2}$ out of an atmosphere containing TEOS following Equation (6), the purity of the layers is expected to be low because carbon-containing traces will be formed. Carbon in a matrix of $\mathrm{SiO}_{2}$ can be detected beyond the $0.1 \%$ detection limit by wavelength-dispersive $X$ ray electron beam analyis (WDX) or by energy-dispersive $X$ ray analysis (EDX) beyond $1 \%$.

But how to get information in polymers which consist only of carbon [as diamond or carbon nano tubes (CNTs), or carbon and hydrogen, or carbon and fluorine (teflons)]? What can be expected from the numerous types of spectroscopy? We distinguish between chemical and physical methods. Chemical methods simply count atoms or bonds in various ways. Physical methods use indirect ways to reveal atoms or electrons, for example by measurements of the conductivity (conductivity, mobility, electron density), Hall voltage (carrier density, type of carrier $\oplus$ or $\ominus$ ) ...

- In polymers, the unsaturated double bond of $s p^{2}$ or $s p$ character of a monomer will be changed to a saturated bond with $s p^{3}$ character. This is revealed by vibration spectra (IR or Raman). However, it is not all quantitative even in high dilution. Moreover, IR spectroscopy is very sensitive to impurities but lacks for matrix effects. Therefore, the intensity does not scale with concentration (of impurities). Since the intensity is proportional to the square of $\frac{\partial \mu}{\partial x}$ with $\mu$ the dipole moment and $x$ a length, it is very insensitive for bonds with low dipole character. But the $\mathrm{C}-\mathrm{H}$ bond is unpolar which causes very weak IR intensities! Therefore, Raman spectroscopy is the method of choice [40]. 
- Residual electrons in radicals can be detected by electron spin resonance (ESR) [41]; this is a very sensitive method. However, it gives only information of the number (or density) of the unsaturated ends of the polymeric chains. But it does not discriminate between these intended radicals and other unintended radicals which might have been generated during plasma excitation.

- For diamond, Raman spectroscopy is second to none as quality probe. Only one absorption line, the symmetric valence vibration at $1332 \mathrm{~cm}^{-1}$ must appear to prove the spectroscopic purity of diamond [42,43]. That is far beyond the demands on purity which have been used over centuries (from the four Cs cut, clarity, color and carat, the clarity is content with a flawless view through a microscopy with just 10-fold magnification!).

- From their exploration by Iijima in 1991 [35], CNTs have attracted extreme interest. CNTs are often prepared in hot plasmas. Laser ablation and arc discharge are the most common techniques. Simple CVD requires a catalytic guidance. Often, $\mathrm{Fe}$ is applied as catalyst which can easily be proven by optical emission spectroscopy in inductively-coupled plasmas (ICP-OES) [37]. The benzene rings consist of only $s p^{2}$ carbon atoms.

In fact, single-walled carbon nanotubes are cylinders consisting of hexagonal base units of benzene which form a single sheet of graphene. In contrast to a single sheet of graphene which is extended to $\infty$, the plain sheet is rolled up into the cylinder whose diameter is very small against its length [44]. Therefore, it can be regarded as one-dimensional hollow wire with a finite number of benzene units around the perimeter of the wire. Since the radius of curvature is very small, CNTs exhibit a sharp curvature around an imaginary one-dimensional thread which changes the optical qualities dramatically [40].

Electrons have eigenstates quantized with the circumference of the nanotube. The electronic band structure can be developed from the benzene unit which is folded with the perimeter of the tube [40]. Also, photons and other quasiparticles are expected to exhibit a discrete wavelength spectrum quantized with this perimeter. In the direction of the nanotube, the states are continouos.

But as in graphite, the distinct graphene structure with $s p^{2}$ hybridized carbon atoms in a two-dimensional radial structure is loosely held together by weak van-der-Waals bonds in the third dimension. Therefore, the multi-walled nanotubes exhibit just a smaller radial bonding force, compared with the stronger tangential component which defines the structure.

Since a pure CNT is composed only of $s p^{2}$ hybridized carbon atoms, the absence of IR bands which are caused by single bonds prove their purity. As Caccamo et al. have shown, the FTIR spectra of CNTs lack any contour [45]. In the same study, they reported also Raman data. As it is explicitely analyzed by Thomsen and Reich [40], two prominent band systems can be distinguished,

- $\quad$ the $G$ band at $1575 \mathrm{~cm}^{-1}$ which is caused by the valence vibrations of $s p^{2}$ hybridized graphene $\mathrm{C}$ atoms-they form the concentric cylinders of the various types of CNTs [single-wall (SWCNT), double-wall (DWCNT), or multiwall (MWCNT)], and are described as tangential vibrations along the nanotube walls [46,47], and

- $\quad$ the $D$ band at $1300 \mathrm{~cm}^{-1}$ is due to $s p^{3}$ hybridized $C$ atoms with dangling bonds which terminate the graphitic structure.

- Additionally, the first overtone of the $G$ band occurs at approx. $3200 \mathrm{~cm}^{-1}$.

As result of these considerations, it will be evident that just analytic reports on diamond and CNTs show or comment a Raman spectrum to prove purity, whereas papers describing plasma polymerization lack this information, especially when they describe polymerization reactions of monomers which will never polymerize by a thermal method. Among them are the saturated aliphatic compounds. $\mathrm{CH}_{4}$ can never be thermally polymerized-which is an easy task for a low-pressure plasma. 
It should have become clear that it is very difficult to get analytical information for $\mathrm{C}-\mathrm{H}$ polymers, for the surface of the layers and their bulk. Therefore, as the most prominent date, still the layer thickness remains. Even the $X$ ray density is impossible to gain since no polymer will crystallize-with the glorious exception of diamond. Therefore, only the layer thickness (growth rate) can be compared with simulations.

\subsection{Mechanisms of Polymerization}

A lot of excellent review articles and books are available which describe the mechanism of bond formation. Besides Yasuda's book with his pioneering work [23], the book Plasma Deposition, Treatment, and Etching of Polymers, edited by Riccardo d'Agostino, Daniel Flamm, and Orlando Auciello [48], Möller's report [49], and especially for deposition of parylene films the monography by Fortin and Lu [50]. They all describe reactions in a vacuum which is generated by rotary vane pumps (i.e., base vacuum not better than 1 mTorr or fractions of a Pa). We have seen in Section 2.1 that the term RIE in capacitively-coupled discharges which are excited in parallel-plate reactors is simply an euphemism, and we have further seen that for PECVD, this does not necessarily mean a disadvantage because loaded particles cannot be polymerize. But what does the calculation of the number densities of reactive species in Section 1.5 mean for the deposition process?

Vacuum and Residual Gas

The vacuum that can be achieved with rotary vane pumps is in the range of approximately $1 / 4 \mathrm{~Pa}$ (1 mTorr). In air (80\% nitrogen), this means a number density of $3.54 \cdot 10^{13} / \mathrm{cm}^{3}, 20 \%$ are approx. $7 \cdot 10^{12} / \mathrm{cm}^{3}$. As it explicitely calculated in Example II, this vacuum causes the partial pressure of the residual oxygen to be on the same order of magnitude as the layer forming component.

However, for a radical mediated polymerization mechanism, oxygen is an outstanding terminator because $\mathrm{O}_{2}$ itself is a diradical. Thus, all the reaction mechanisms discussed so far are questionable. For the application of plasmas that induce dimer dissociation into chain-building monomers, this problem also holds true for the initial reaction. We estimate this problem using a reactor with $100 \mathrm{~L}$ in volume which is flooded with $10 \mathrm{sccm}$ of monomeric gas $\mathrm{M}_{2}$. This gas is cracked by plasma into two halves, generating two $M \cdot$ radicals.

Example 2. For a base pressure of $0.5 \mathrm{mTorr}(1 / 10 \mathrm{~Pa})$, the number density of residual oxygen is $1.7 \times 10^{13} / \mathrm{cm}^{3}$. For a "normal" process, the evaporation rate is $10 \mathrm{sccm}$ in our large reactor (volume: $100 \mathrm{~L}$ ), after the thermal cleavage, it doubles its value to $20 \mathrm{sccm}$. Argon is added to dilute the vapor. In the equimolar case, the pumping speed is approximately constant at $2.4 \mathrm{~L} / \mathrm{s}$. Hence, the number density of the monomers is $3.7 \times 10^{15} / \mathrm{cm}^{3}$, which results in a ratio of monomers to oxygen molecules of only 220. For comparison, if Al is being sputtered reactively in an ambient doped with $\mathrm{O}_{2}$ at a typical deposition rate of $1 \mu \mathrm{m} / \mathrm{min}$, a partial pressure of just $0.5 \mathrm{mPa}\left(5 \times 10^{-6}\right.$ Torr $)$ is sufficient for complete oxidation (56 atomic percent of oxygen) [51]. Using the equation connecting current density to drift velocity $j=\rho \cdot v$ to estimate the density of the Al atoms located between the electrodes, it is evident that termination will most likely occur by oxygen capture. In the case that $E_{\text {kin }}$ equals $4 \mathrm{eV}$, the initial velocity of the Al atoms is approximately $28 \sqrt{\frac{4}{3}}=33 \times 10^{5} \mathrm{~cm} / \mathrm{s}$. If the energy is reduced to $1 \mathrm{eV}$ when the atom hits the surface, the velocity still remains at $2 \times 10^{5} \mathrm{~cm} / \mathrm{s}$. With an area of $8 \AA^{2}$ required for one $A$ l atom, a flux of $8 \times 10^{16}$ atoms $/ \mathrm{cm}^{2} \mathrm{sec}$ results, which translates to a density of $11 \times 10^{11}$ atoms $/ \mathrm{cm}^{3}$. The partial pressure of oxygen is lower by only one order of magnitude $\left(1.6 \times 10^{11}\right.$ atoms $\left./ \mathrm{cm}^{3}\right)$ !

So we see that the termination reactions are very important to determine the equilibrium of the polymeric reaction when organic chains are concerned. This does not hold true for coating inorganic layers for which oxygen is a required reactant, as for the coating of $\mathrm{SiO}_{2}$ out of TEOS or HMDSO $[52,53]$. And therefore, all the mechanistic considerations in vacua which are solely pumped by rotary-vane pumps are questionable. This is explicitely 
admitted by Möller [49]. The absence of other lines than $1332 \mathrm{~cm}^{-1}$ in the Raman spectrum of ICP-diamond reveals: a base vacuum lower of at least three orders of magnitude is required to coat layers which are free of oxygen. The application of a turbopump or a diffusion pump is a must-have to draw mechanistic conclusions.

It is evident that the stripping of hydrogen according to Equation (13) is essential as start reaction which is followed by an avalanche process to lower grades of : $\mathrm{CH}_{2}$

double radicals and even $: \mathrm{CH}$ triple radicals [Equations (14) and (15)]. At pressures below 1 Torr, this should be happen in a one-step reaction, above this value, also two reactions can occur. The growth rate is then compared with model simulations. The most famoust simulator is Mark Kushner's Hybrid Plasma Equipment Model (HPEM) which contains all the reactions, their dependence on process parameters (pressure, electron temperature, plasma density ...) for various excitation modes (CCP, ICP, ECR, helicon, dual frequency at pressure below 10 Torr). It was invented by him, started as Virtual Plasma Equipment Model (VPEM) [54] and has been maintained and improved by hundreds of his students [55]. But prerequisite is: this data must be provided by plasma diagnostics and surface diagnostics.

\subsection{Comparison}

The layers which are deposited out of a vapor or a low-pressure plasma are polymers, although this term is normally coined for organic compounds. However, also $\mathrm{SiO}_{2}$ oder $\mathrm{Si}_{3} \mathrm{~N}_{4}$ are molecular polymers, chemically bound by single bonds. In contrast to carbon, single bonding is the normal connection between atoms beyond the second period with oxygen or nitrogen. Additionally, the heat of formation is extremely negative (exothermic), and that results in very stable bonding. Therefore, even hard plasma conditions will yield layers with an almost perfect lattice.

To confirm the character of the chemical bond and to detect impurities, vibration spectroscopy (IR or Raman) is the method of choice. X-ray diffraction does not work with samples which exhibit a thickness of just some microns. Often, highly-resolved scanning transmission electron microscopy can be used to prove the crystallinity of the layers.

In contrast to these directions to get comprehensive information of the layer quality, these methods mainly fail for organic polymers. This is due to the fact that carbon can build not only single bonds but also double or even triple bonds to its direct neighbors which favors three-dimensional branching. To make matters worse, termination reactions can stop layer growth which leads to a broad spectrum of polymeric particles-not only one-dimensional chains. Both issues typically lead to a broad spectrum of reaction products which simply make it impossible to define clear and sharp properties of the product.

It is just diamond with its perfect $s p^{3}$ hybridized $C$ atoms which allows a clear confirmation of purity and crystallinity. In CNTs, all graphitic bonds must inevitably terminate with a dangling bond of an $s p^{3}$ atom causing a purity less than $100 \%$. But both the modifications of carbon can be gaged by the method of vibration spectroscopy-only to Raman, because IR vibration spectroscopy fails due to the demand of a timely changing dipole moment.

\section{Deposition of Parylene}

\subsection{Monomer Formation and Polymerization}

As an example of the issue CVD $\rightleftharpoons \mathrm{PECVD}$, the polymerization of poly-p-xylylene, PPX, is discussed in the concluding chapter. PPX is a polymer with remarkable properties. Its permeability for gases is extremely low, just one order of magnitude poorer than the value of inorganic films (Figure 9).

It is an FDA-approved organic polymer what explains the wide-spread interest for coatings of implantates.

Chemically, PPX with its trivial name parylene is a good example for the discussion $\mathrm{CVD} \rightleftharpoons \mathrm{PECVD}$ since the monomeric intermediate is well stabilized by two aromatic rings which guarantee the stability of the double radical with the two terminal methylene 
groups. This forces the direction of the intended polymerization, a linear growth to a onedimensional thread molecule. However, for the heterogenous polymerization which occurs out of the vaporous phase on a solid, the chain length or dispersity cannot be influenced.

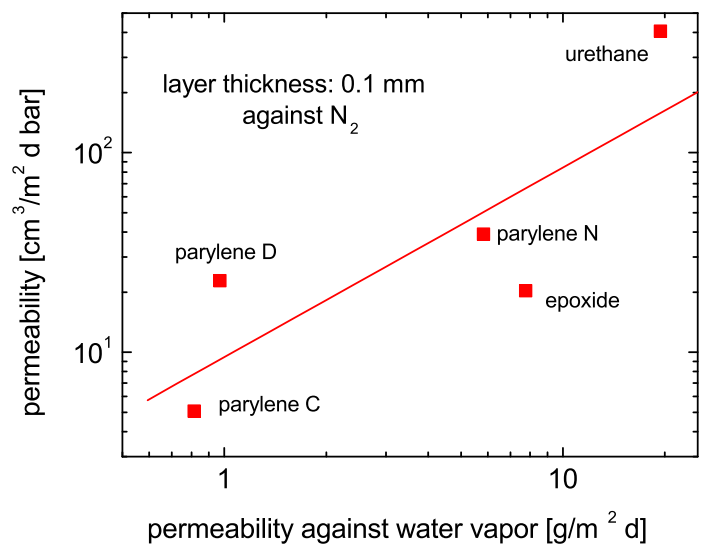

Figure 9. Barrier properties of some derivates of parylene.

In the following, several issues are discussed, starting with the deposition process which justifies the term CVD for this process, the IR determination of the purity and the steering of the grain size. The roughness of the surface and its conduct against liquids reacts very sensitively on the excitation conditions and is chosen to be described in the last section.

Numerous derivates exist, starting from the unsubstituted molecule of Equation (17). In the first type, the $\mathrm{H}$ atoms of the benzene core are substituted by halogens or the amino group $\left(\mathrm{NH}_{2}\right)$, in the second type, the methylene bridges between the two benzene cores are substituted by halogens.

According to Gorham, PPX is deposited by chemical vapor deposition (CVD) by thermally cracking the precursor di-parylene $\mathrm{N}(\mathrm{DPX})$ at $700^{\circ} \mathrm{C}$ into the the monomer MPX, which forms polymeric chains of poly-p-xylylene (PPX) [3,4]. This reaction can occur either in the gas (volume polymerization) or on the cold surface (surface polymerization) Equation (17).

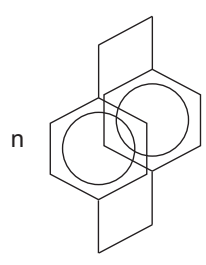

DPX<smiles>CCCc1cc(C)ccc1C</smiles>

MPX<smiles>Cc1ccc(C)cc1</smiles>

PPX

According to Equation (17), the polymeric reaction is of radicalic character and happens at two docking positions at the two methylene groups in $p$-position of the benzene ring. The double radicalic function of the xylylene monomer is stabilized by the aromatic ring structure. Cleavage of a C-C bond is favored by more than $60 \mathrm{~kJ} / \mathrm{mol}$ compared with the cleavage of a C-H bond ( $413 \mathrm{vs} .348 \mathrm{~kJ} / \mathrm{mol}$ ).

Therefore, the predetermined breaking point is the bond between the two methylene groups, irrespective of whether the reaction is thermal or plasma assisted (Figure 10).

Once the dimer is broken at this bond, the two terminal primary $\mathrm{C}$ atoms can only react with an identical counterpart, thereby favoring the formation of just one reaction track resulting in long one-dimensional thread molecule. 


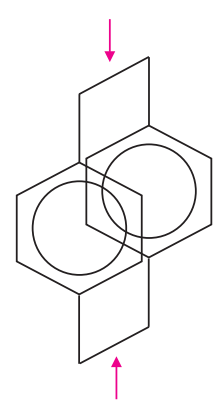

Figure 10. In the precursor diparylene, the two red arrows mark the breaking point of the molecule.

The established CVD process for parylene deposition consists of three main steps using the set-up in Figure 11.

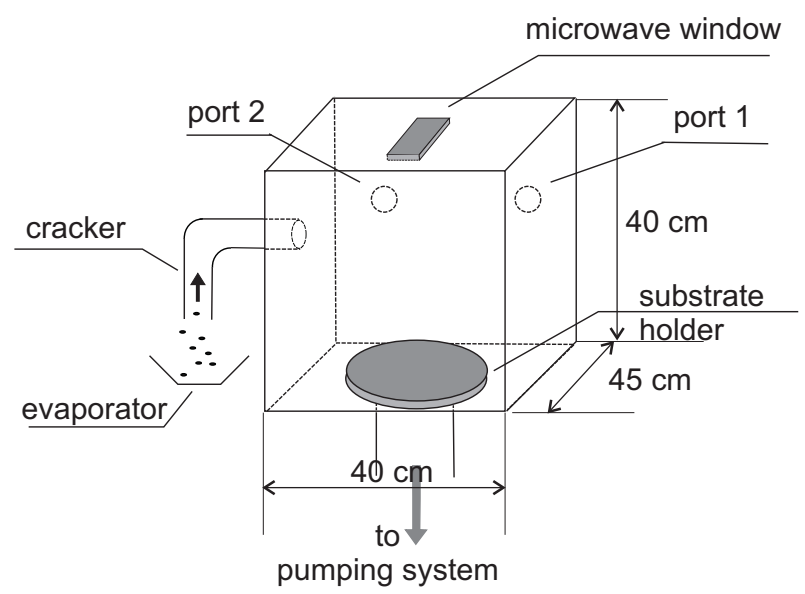

Figure 11. CVD reactor with microwave coupling unit which is used to deposit PPX. The filmbuilding monomers enter the reactor on the LHS and will be pumped out through the annular gap below the circular substrate holder at the bottom [56]. The pump is protected against organic vapor by a cold trap $\left(-90^{\circ} \mathrm{C}\right)$.

First, the dimeric precursor is converted from the solid state into the gaseous phase. This is typically conducted at a reduced pressure of a few pascals and at a temperature between $100^{\circ} \mathrm{C}$ to $150^{\circ} \mathrm{C}$. Under these conditions, the dimeric precursor is sublimated. In the second step, the gaseous di-parylene is made to go through a pyrolysis process at temperatures of typically $700^{\circ} \mathrm{C}$, wherein it cracks into its two monomeric constituents. The output of the cracker unit is connected to the vacuum chamber by a electrically heated allocator, which is maintained at a temperature of approximately $140^{\circ} \mathrm{C}$ to avoid any precipitation. In the third and last step, the monomeric parylene is guided into a vacuum chamber at room temperature, where the molecules react to form long polymeric chains which deposit themselves as homogeneous films in a heterogenous reaction. Any part in the recipient will be coated. The table with the substrates at the bottom of the reactor is rotable to equalize possible differences in vapor density. The process of polymerization can also begin as homogeneous reaction in the vapor. The properties of the deposited layers can be influenced by varying the process pressure, degree of dilution, vaporization temperature and pyrolysis temperature, with the microwave option, additionally by MW power. Furthermore, by doping the recipient atmosphere with dopant gases, the deposition rate and the film properties can be modified. On a molecular basis, the two described processes happen as shown in Equation (17). The above described method is extensively described in the literature as Gorham method $[3,50]$.

To summarize, this series of reactions occurs in a CVD reactor (Figure 11), which is continuously perfused by the polymer-generating vapor and additional doping gases. Vapor enters through a heated pipe and reacts either in the volume (gaseous reaction) or 
on cold surfaces (solid state reaction) to a polymer by chain-building depending on the operating pressure and degree of dilution. The simple reaction path of the chain polymerization outlined in Section 1 applies only if the atmosphere is free of scavenging radicals, particularly molecular oxygen, which acts as an ideal terminator of chain growth [22] In this field, several kinetic issues have to be addressed, from diparylene evaporation to the final step of polymer deposition.

In the following, some issues for both excitation methods are investigated.

- One of the most prominent issues which is easily available is the deposition rate. This property mainly depends on the rate of evaporation and the extent of monomerization, in the case of CVD, also on the dilution with inert gases (this dilution is difficult to investigate for PECVD).

- Is the polymerization controlled by diffusion?

- In contrast to the surface polymerization, which is supposed to be a 1st order reaction at low monomeric densities, is the volume polymerization at high monomeric densities a reaction of 2 nd order?

- Organic reactions are always equilibria. Therefore, the yield is an important property for production purposes.

- Do the two different excitation modes generate coatings with different qualities?

- What happens to the dimers when they are exposed to microwaves?

- What are the morphological changes of the coatings between these two different methods of excitation?

3.2. $C V D$

\subsubsection{Vapor Pressure}

For both the processes the first step is the same. The evaporation strictly follows a Clausius-Clapeyron law (cf. Figure 12). The slope is the heat of evaporation which has been determined to $0.72 \mathrm{eV}$ [56].

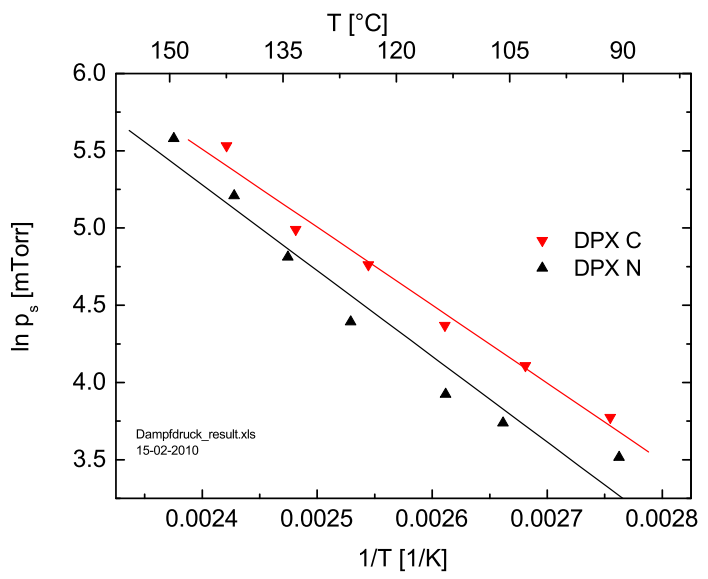

Figure 12. The vapor pressure strictly follows a Clausius-Clapeyron behavior [56].

\subsubsection{Equilibrium of Dissociation}

As the dimers are cleaved thermally, the heat of dissociation can be determined by mass spectrometry. We found a value of $1.68 \mathrm{eV}$ for the unsubstutited dimer (cf. Figure 13.1, $y$ : relative intensity of ion currents $I$, referred to the maximum value at $700^{\circ} \mathrm{C}: y(T)=$ $\left.\frac{I(T)}{I\left(700{ }^{\circ} \mathrm{C}\right)}\right)$ for the two masses 104/103 (104: mass of the cleaved monomer MPX $\mathrm{CH}_{2}-\mathrm{C}_{6} \mathrm{H}_{4}-$ $\mathrm{CH}_{2}$, 103: mass of the cleaved monomer MPX $\left.-1 \mathrm{H}: \mathrm{CH}-\mathrm{C}_{6} \mathrm{H}_{4}-\mathrm{CH}_{2}\right)$. But even more remarkable is the diagram for the masses $32 \mathrm{amu}$ (mother peak of $\mathrm{O}_{2}$ ) and 103/104 amu against temperature (Figure 13.2). This diagram clearly prooves the scavenging of oxygen by the freshly cleaved monomers. 


\subsubsection{Deposition Rate}

The thickness of the deposited layers has been measured on samples which were placed at a distance of approx. $30 \mathrm{~cm}$ from the cracker outlet tube. In Figure 14, the deposition rate $(D R)$ as function of total pressure for two different temperatures is shown. The flow of MPX only depends on the temperature of evaporation and rises exponentially with rising absolute temperature (cf. Figures 12 and 14.1). Since the slope of the curve of evaporation (Figure 12) matches the slope of the curve of deposition (Figure 14.2), the thermal cleavage does not cause any additional effect. Dilution with argon at constant MPX flow reduces DR with an exponential decrease (Figure 14.1,2).
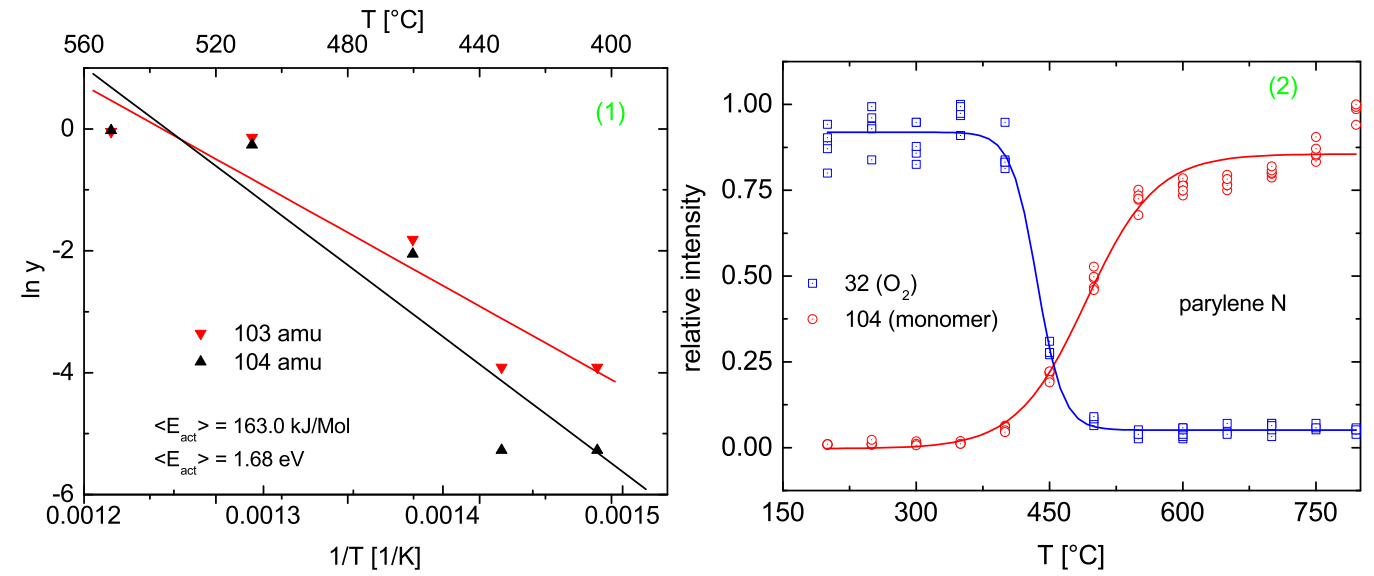

Figure 13. The equilibrium of dissociation [Equation (17)] is evaluated by mass spectrometry. (1): Arrhenius plot of masses 103 and $104 \mathrm{amu}, y(T)=\frac{I(T)}{I\left(700^{\circ} \mathrm{C}\right.} ;(2)$ : peaks at $32 \mathrm{amu}\left(\mathrm{O}_{2}\right)$ and $104 \mathrm{amu}(\mathrm{MPX})$. Oxygen traps the monomers [56].
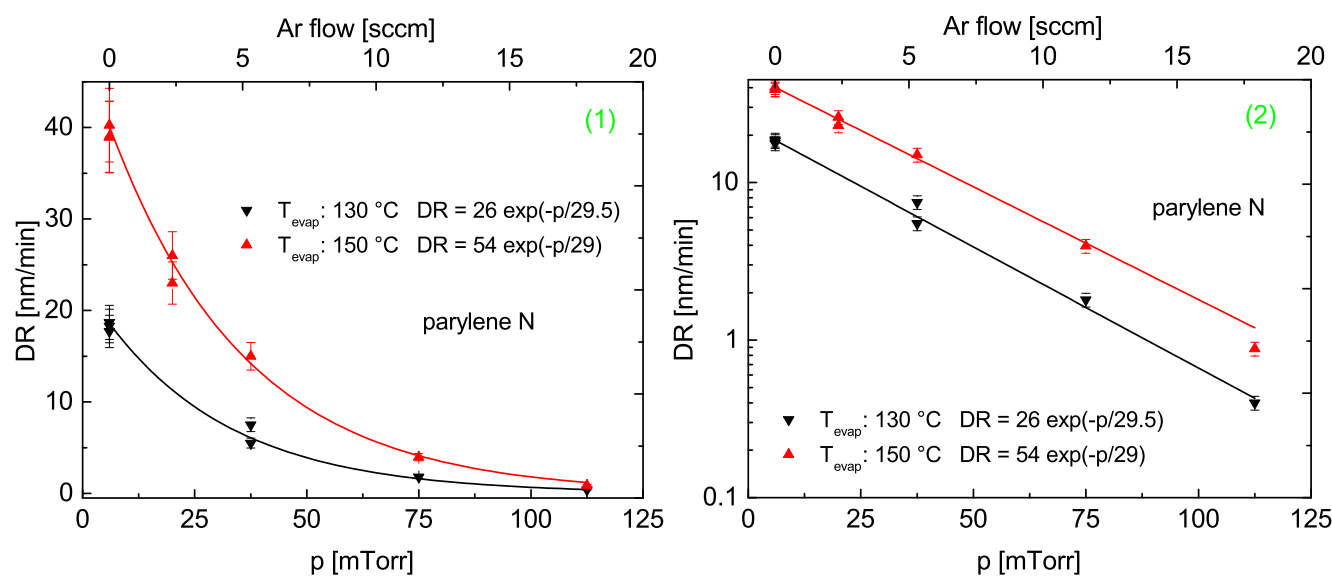

Figure 14. Deposition rate DR of MPX-N as function of reactor pressure $p$ for two different temperatures, (1): linear scale, (2): logarthmic scale. The deposition rate increases exponentially with rising absolute temperature, and decreases exponentially with rising argon flow [56].

\section{Models for the Deposition Rate as Function of Pressure}

The reactor spatially separates the regions of activation (cleavage of dimers) and polymerization (oligomers or polymers in the vapor vs. polymeric deposit as surface reaction). The deposition rate $D R$ depends on two parameters, the availability or density of monomers and on a steric factor. Two monomers are generated by the homogeneous fission of the dimeric precursor in the cracking unit. For the geometry of this reactor, a complete turnover to monomers is expected.

For the dependence on pressure, several experimental findings differ between an exponent of 1.5 [6] and 2 [57]. Models for the polymerization have been developed by Ganguli [6], Fortin [50], and Beach [58]. For a surface reaction, the diffusion of reactive 
species to an active site plays an important role. After the initial reaction of three monomers which form a triple unit with two reactive centers, chain growth is proportional the the monomeric density and the diffusivity of the monomer in the film. This leads to an exponent of only $3 / 2$ for the overall pressure dependence [6,58]. But it is remarkable that in the small pressure interval covered, the experimental data can be fitted well by both approaches.

At low vapor densities, surface polymerization is favored which is passed by volume polymerization if the pressure is raised. This behavior defines an upper limit of the operating pressure due to the onset of parasitic snow formation (approx. 100 mTorr) [6].

It should be noted that the reaction is not diffusion-controlled $[59,60]$; the rate at which the radicals strike the surface was estimated to exceed that at which a radical is effectively absorbed by the growing chain by approximately three orders of magnitude [58]. This low sticking coefficient is mandatory for the excellent conformal coating behavior, and the rate-limiting step happens on the surface.

As our interest is focused on layers with a defined porosity which can only be achieved by a low deposition rate, diluting the chain-building vapor with an inert gas is one possibility to enhance the film quality.

This is analyzed by variation of the evaporation temperature of the dimeric precursor (following the Clausius-Clapeyron equation), and diluting the reactive gas with argon. For a reaction of first order, the deposition rate is expected to decrease exponentially with a $p^{1}$ in the argument and same slope for different evaporation temperatures. In Figure 15, this behavior is depicted in two (repeated) representations as function of total pressure [1 (linear scale) and 2 (logarithmic scale)] and as function of the percentage of partial pressure monomer $x=f_{\mathrm{MPX}} /\left(f_{\mathrm{MPX}}+f_{\mathrm{Ar}}\right)$ for two models-in fact, $x$ is the molar fraction. For the chemical equilibrium between monomer MPX and dimer DPX [Equation (17)], its constant is given by Equation (18)

$$
K_{\text {diss }}=\frac{p_{\mathrm{MPX}}^{2}}{p_{\mathrm{DPX}}}
$$

which is followed by the (intended) surface reaction MPX $\rightarrow$ PPX. The equilibrium is written inverted [as in the derivation of the solubility product, Equation (19)]:

$$
K_{\mathrm{p}}^{\prime}=\frac{p_{\mathrm{MPX}}}{p_{\mathrm{PPX}}} .
$$
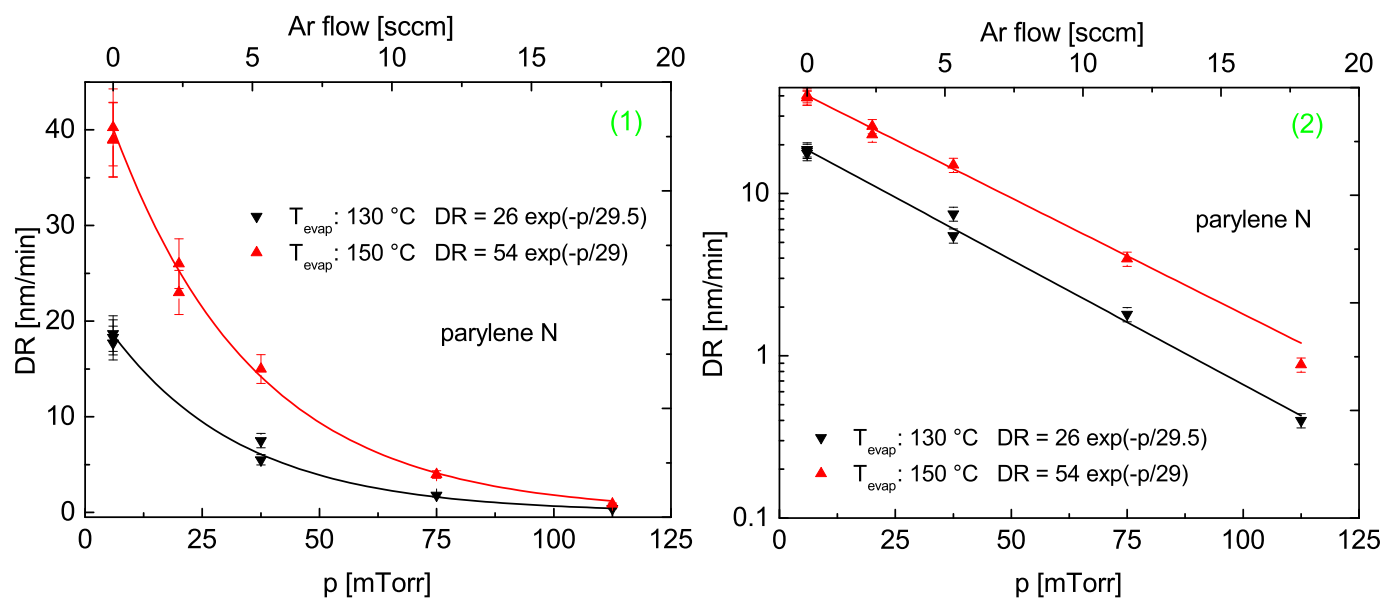

Figure 15. Cont. 

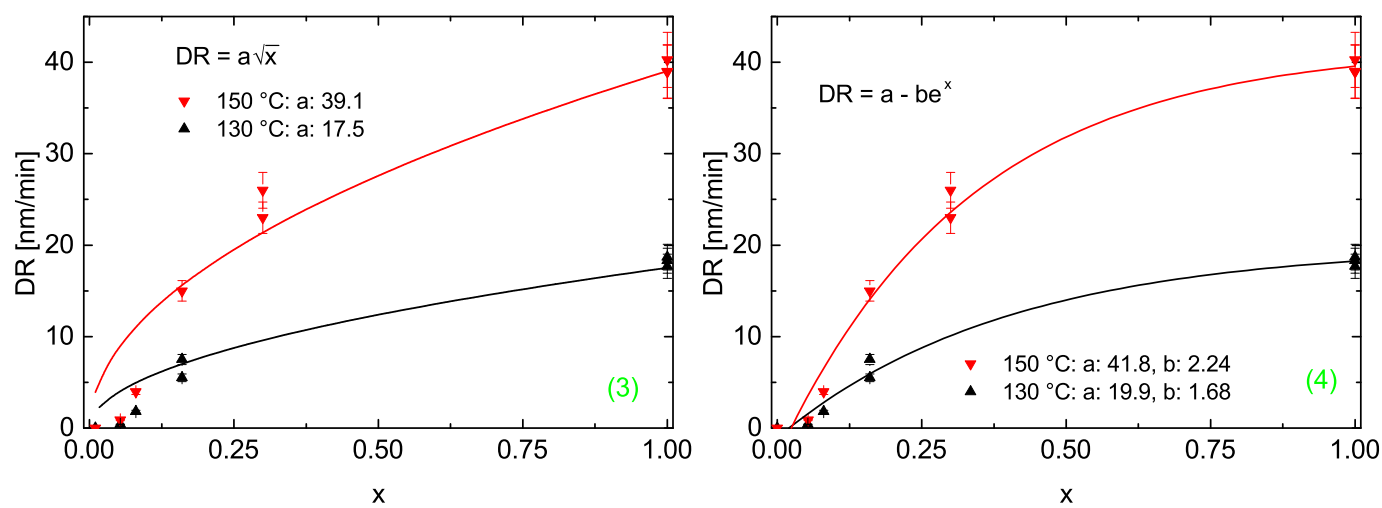

Figure 15. Deposition rate $D R$ of parylene $\mathrm{N}$ as function of reactor pressure $p(\mathbf{1}+\mathbf{2})$, and of the molar fraction $x$ $\left(x=f_{\mathrm{MPX}} /\left(f_{\mathrm{MPX}}+f_{\mathrm{Ar}}\right)\right)$ for two models. By diluting the vapor with argon, the reaction is forced to surface polymerization (reaction of first order), best visible by the linear logarithmic slope [61]. Model (3): rate-limiting step is condensation of the monomer, model (4) due to Fortin, which includes surface diffusion as rate-limiting step.

Since PPX is a solid with an activity which equals unity, it is integrated into the equilibrium constant $K_{\mathrm{p}}$ yielding Equation (20)

$$
K_{\mathrm{p}}=K_{\mathrm{p}}^{\prime} p_{\mathrm{PPX}}=p_{\mathrm{MPX}}
$$

expressing diffusion control: condensation is followed by the chemical reaction (enlargement of the polymeric chain) with a yield of $100 \%$. Including (18), this leads to the final Equation (21)

$$
K_{\mathrm{p}}=p_{\mathrm{MPX}} \vee \sqrt{K_{\mathrm{diss}} p_{\mathrm{DPX}}} .
$$

This poor dependence is shown in Figure 15.3. A more realistic model takes into account that the growth process consists of at least two steps. The first is the landing process somewhere which does not require energy (adsorption process or physisorption). This thermally activated MPX starts roaming until it will react with the end of a polymeric chain, thereby generating a new radicalic function at the prolonged end of the chain which becomes the new active site. This roaming step, however, requires a certain activation energy. But even high an activation energy were useless unless the MPX double radical would not find a reactive site. Figure 15.4 shows Fortin's approach, which connects the terminating value for PPX, here denoted $a$, with an exponential term $c^{x}$ and an preexponential factor $b . b$ is mainly responsible for the surface diffusivity, and $\mathrm{e}^{x}$ which includes the order of the surface diffusion reaction with its diffusion coefficient, $x$ being the molar fraction of MPX [62]. Best fits were found for a coverage of reactive sites in the $0.1 \%$ region, i.e., only one of thousand sites is reactive. Evidently this fits the experimental data.

\subsection{Plasma Enhanced Chemical Vapor Deposition}

For vacuum levels generated by rotary vane pumps, recording of mass spectra is only feasible for ambients with thermally cleaved parylenes. A normal recording of an ambient with diparylene significantly changes once the plasma is ignited, as all of the peaks disappear without the exception of hydrogen. This behavior is most likely caused by the high residual level of oxygen, which is an excellent radical scavenger. By this reaction, large molecules are built up, which evade mass spectrometric analysis. Additionally, the coatings are opaque and exhibit very low densities. Hence, all of the reaction mechanisms discussed so far are questionable. According to these mechanisms, the polymerization is second order at higher pressures but first order at lower pressures [10].

Determining the reaction order of polymerizations with plasma support is already difficult in a closed reactor. However, in a flow reactor, aditional features complicate the process, which were first addressed by Yasuda [22]. In plasma supported cleavage, the number density and pressure are enhanced and change the flow $\Gamma$ (compared with a liquid, vapor is highly compressive), which is described by Yasuda using two empirical 
parameters, $a$ and $b$, and the relation $(1 \leq b \leq 2): \Gamma=a p^{b}$ [22]. Moreover, other molecular fragments are generated that further complicate the mechanistic discussion. The most prominent impact is a maximum in the deposition rate as a function of flow, which indicates two counteracting influences. In the region of monomeric deficit, at low flow values, the deposition rate scales with flow and the number density of the film-building component (regime of surface polymerization, low number density with transparent layers) [22] At high flows, in the region of power deficit, this relation becomes inverted, and the region of volume polymerization with opaque layers is entered. Therefore, the maximum will be achieved at lower plasma powers.

\subsubsection{Plasma Activation}

From Figures 13, it is evident that for effective thermal cleavage, a certain threshold temperature is required. This does not hold true for plasma activation, where the monomers are excited to higher electronic levels from which further reactions can readily occur (formation of radicals and ions). As has been outlined by Yasuda, the yield of the polymerization, i.e., thickness and density of the deposited layer as the simplest parameter, but above all the purity, is a trade-off of the intended reaction paths (i.e., the dissociation) and unintended reactions, here: further destructions of the monomer at higher power input (cf. Figure 4 [22] and Figure 16).

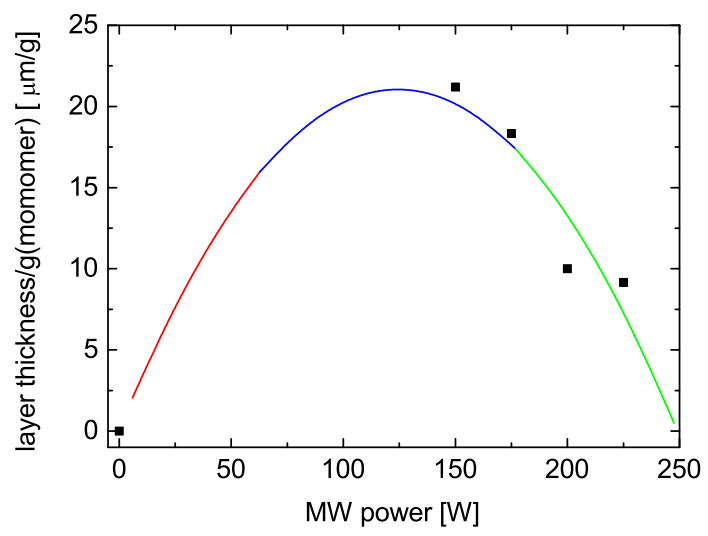

Figure 16. According to Yasuda, the regimes of power deficit and abundance of power are separated by optimum power input [23].

The maximum of the parabola which describes the deposition rate is supposed to the onset of passivation [23] which is caused by the rising fragmentation of chain-building monomers (100 W corresponds to approx. 1.1 W/L). With this optimized power input, the growth rates are compared made up of layers, which were piled up with the same amount of dimeric parylene (Figure 17). 


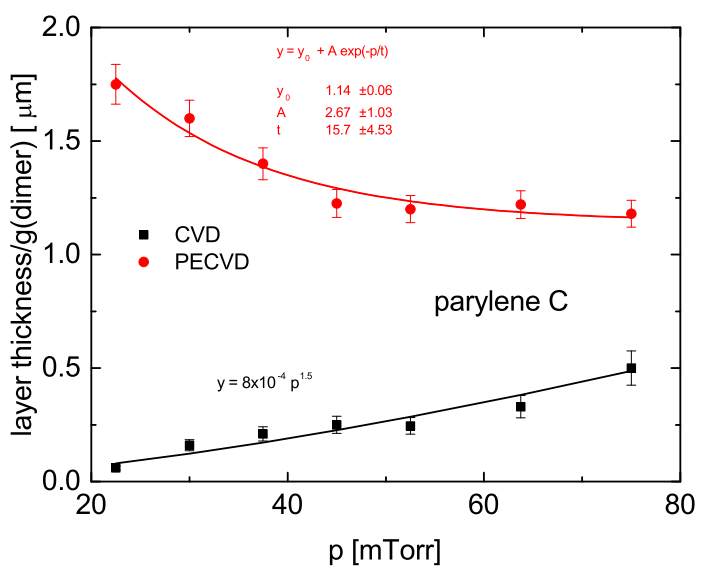

Figure 17. Specific thickness of layers deposited (referred to the mass of dimer) as a function of pressure $p$ for CVD and PECVD (MW power $125 \mathrm{~W}$ ). Diluent is argon. Plasma activation generates more reactive species than thermal treatment. Due to the lower electron density with increasing pressure, the rate of layer formation decays exponentially.

\subsubsection{Discussion}

Efficiency of Thermal Cleavage

At typical conditions, in our reactor with a volume of $91 \mathrm{~L}\left(40 \times 40 \times 51 \mathrm{~cm} ; T_{\text {evap }}=\right.$ $130^{\circ} \mathrm{C}$ ), we find a flow into the reactor of $9.3 \mathrm{sccm}$ after evaporation, and $18.6 \mathrm{sccm}$ after complete dissociation (i.e., $2.5 \times 10^{20}$ molecules $/ \mathrm{min}$ or $1.51 \times 10^{22}$ dimeric molecules $/ \mathrm{h}$ and $3.02 \times 10^{22}$ monomers $/ \mathrm{h}$ ), which is a total of $50 \mathrm{~m}$ moles or $5.22 \mathrm{~g}$. The area of the reactor is $\left(V=40 \times 40 \times 51 \mathrm{~cm}^{3}\right) 12,320 \mathrm{~cm}^{2}$. If all monomeric molecules would stuck after their first surface hit, that would cause a current density of $j=6.8 \times 10^{14}$ monomers $/ \mathrm{cm}^{2} \mathrm{~s}$, which would result in a layer growth of $3.84 \mu \mathrm{m}$ (density of parylene $\mathrm{N}: 1.1 \mathrm{~g} / \mathrm{cm}^{3}$ ): no losses, no cooling trap required.

At a pumping power of $3 \mathrm{~L} / \mathrm{s}$, the flow of $18.6 \mathrm{sccm}$ of argon would cause a rise in pressure to $10.5 \mathrm{~Pa}$ which equals a number density of $n=5.75 \times 10^{19}$ molecules in $91 \mathrm{~L}$ or $6.4 \times 10^{14} \mathrm{~cm}^{3}$.

According to kinetic gas theory, we would expect a current density to either wall of $4.24 \times 10^{18} / \mathrm{cm}^{2} \mathrm{~s}$, provided the hot monomers are thermalized to $300 \mathrm{~K}$. Are they thermalized? A rough estimation for two conditions, either pure monomer or monomers diluted by argon.

- $\quad$ entering velocity $(T=1000 \mathrm{~K}): 480 \mathrm{~m} / \mathrm{s}, \sigma_{\mathrm{C}_{6} \mathrm{H}_{6}}=88 \AA^{2}, p=10 \mathrm{~Pa}\left(6.4 \times 10^{14} \mathrm{~cm}^{3}\right)$ : $\lambda=1.25 \mathrm{~mm}$;

- $\quad$ entering velocity $(T=1000 \mathrm{~K}): 480 \mathrm{~m} / \mathrm{s}, \sigma_{\mathrm{Ar}}=36 \AA^{2}, p=40 \mathrm{~Pa}\left(25.6 \times 10^{14} \mathrm{~cm}^{3}\right)$ : $\lambda=0.8 \mathrm{~mm}$.

As the reactor dimensions $d$ are some tens of $\mathrm{cms}$, in both cases the ratio of reactor dimension $d \div \lambda$ are in the order of some tens: the vapor is completely thermalized.

From these estimations, we see that more than 6000 collisions with the surface are required to cause a yield of $100 \%(3.76 \mu \mathrm{m})$. Therefore, the process of deposition is reactionrate limited and definitely not limited by diffusion-in good agreement to the modeling work of Rogojevic et al. [63]. In fact, it is a yield of 78\%. To put it another way, more than $1 / 5$ of the monomer will get lost in the cooling trap.

Considering this equilibrium, we can compare the effective pressure rise with increasing temperature with the linear pressure rise without dissociation and with dissociation, but without polymerization (Figure 18). 


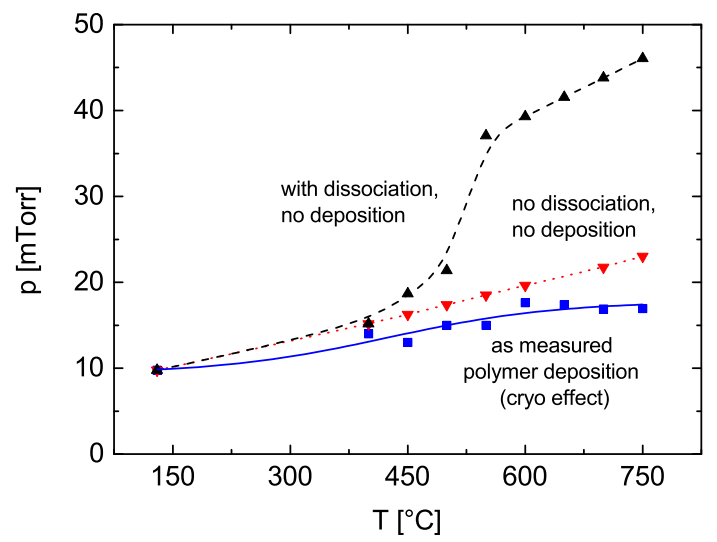

Figure 18. Comparison of the actual pressure (squares, solid, blue) with two scenarios: Linear pressure rise due to the ideal gas law (triangles down, dotted, red), and increased pressure rise beyond $375^{\circ} \mathrm{C}$ (onset of dissociation, triangles up, dashed, black) [4].

Since we work in the regime of viscous flow, we calibrated the flow pressure relation by argon. From this, we calculated a pumping speed of $S=3.0 \mathrm{~L} / \mathrm{s}$. Together with the reactor volume, this leads to a residence time of exactly $30 \mathrm{~s}$. Complete dissociation and perfect pumping without deposition would cause a throughput of $0.235 \mathrm{LTorr} / \mathrm{s}$, and a rise in pressure to $79 \mathrm{mTorr}$ in argon. Due to polymer formation, the pressure rise in monoxylylene is only $6 \mathrm{mTorr}$, and the pumping speed has apparently increased to $S=39.2 \mathrm{~L} / \mathrm{s}$, by more than a factor of 10 .

\section{Efficiency of Plasma Cleavage}

Following the approach of Yasuda and Hirotsu, we rather refer to the thickness per mass of dimer as a function of pressure for CVD and PECVD than to the deposition rate. Since we only refer to one sort of starting molecule, the dimer, it is not necessary to scale it with the molecular weight [64]. By plasma application, the concentration of layer-composing species is enhanced. However, due to the lower electron density with increasing pressure and the decreasing electron temperature, the rate of layer formation decays exponentially [65], but remains above the CVD branch (Figure 17).

\section{Surface Polymerization vs. Volume Polymerization}

From epitaxial growth, it is well-known that the quality of the layers strongly depends on the degree of dilution of the vapor. Since one of the main issues of our research is the dependence of porosity of very thin layers as function of growth conditions and absolute thickness [12], we are interested in slowly grown, but high-quality layers which are the result of a surface polymerization, the volume polymerization forced back by diluting the vapor with argon.

The first step to initiate the polymerization consists of the formation of the dimeric radical out of three monomers, which yields an order of the reaction $n$ of $\frac{3}{2}$ (roughly spoken: 3 for three molecules to be involved in the time-limiting step, $\frac{1}{2}$ for the symmetric cleavage of the precursor) [6,58]. As has been pointed out by Olson, this dimerization is energetically orientated uphill [66]. To form an oligomer, other monomers must dock to this twin radical to form eventually a molecule which exceeds the thermodynamic stability of its reactants. To form such an oligomer in the vapor, high a vapor density is required, which defines an upper limit of the operating pressure due to the onset of parasitic snow formation (approx. 100 mTorr) [6]. At the surface, however, this initial reaction has already occurred, and the propagation to longer chains simply happens as reaction of first order, and chain growth scales with an exponential decrease in vapor density. By diluting the chain-building vapor with argon, the growth rate is reduced (Figure 15.1).

By variation of the evaporation temperature, which enhances the number density of the film-building species following the Clausius-Clapeyron equation, and all other 
parameters being kept constant, we fitted the pressure dependence of the deposition rate by an exponential law for a reaction of first order with almost the same exponent; a criterion for a reaction of first order. From the morphological point of view, formation of snow is definitely suppressed leading to high-quality films at the expense of a lower growth rate (Figure 19).
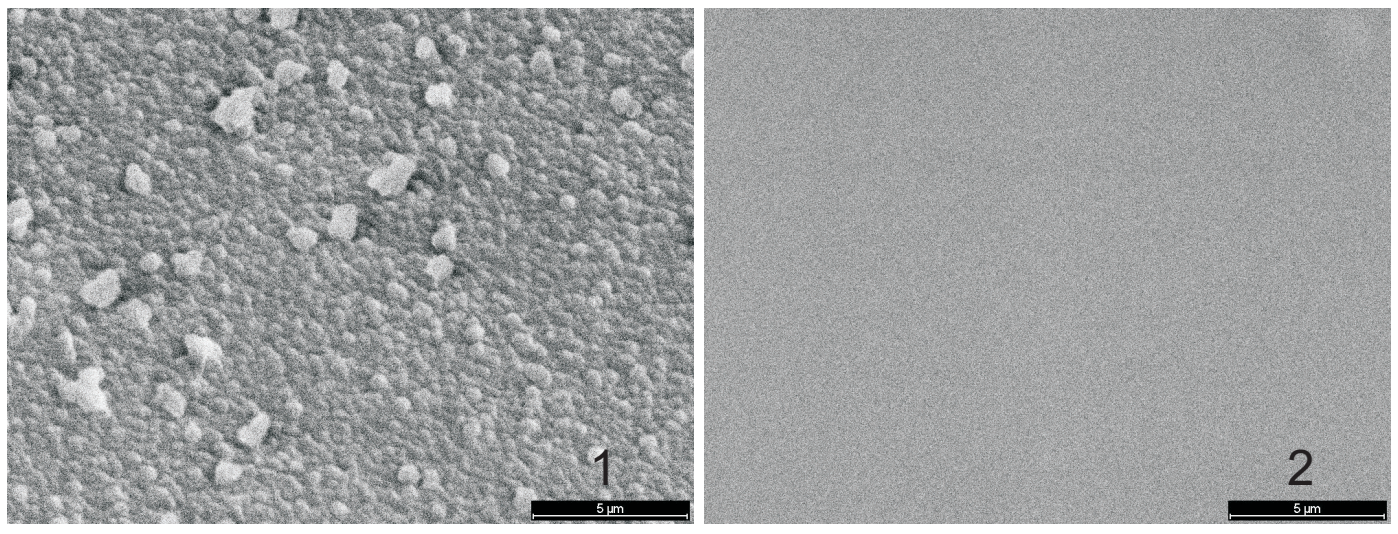

Figure 19. Parylene N, deposited in pure atmosphere of MPX [(1) total pressure: 6 mTorr] and diluted by argon [(2) total pressure: $50 \mathrm{mTorr}$ ], scaling bar is $5 \mu \mathrm{m}$. At constant partial pressure of the monomer, the volume polymerization at low pressure is effectively forced back.

There is almost no difference in roughness between CVD and PECVD. Therefore, we must conclude that it is mainly volume polymerization which causes the growth of flakes. When these flakes deposit it results in a roughened surface.

\subsection{Comparison of Properties \\ 3.4.1. Spectral Identification}

Whereas PECVD is well established to deposit inorganic layers which are well-defined in stoichiometry and lattice structure, there exists a broad mental reservation what the chemical structure of coating is concerned. This ressentiment is mainly fueled by the fragmentation reactions which cause further branching reactions along the reaction path (cf. Section 2.2.2). In the end, a no-stoichiometric molecule results. And the deposited layer is not only subject to attacks of fast ions and electrons, but also to energetic UV radiation. In particular, it is well known that oxygen-containing polymers like PMMA are prone to rapid degradation. Other polymers remain more stable, especially those which contain a benzene ring, for example polystyrenes. And the parylenes also contain this stable unit.

The first question which has to be answered in a positive sense is whether the ring structure has still "survived" or not with reasonable deposition rates. And the second question: does a threshold power exist for destroying the ring structure?

For identifying functional groups, we applied Fourier-Transformed Infrared Spectroscopy (FTIR) of layers which were up to $1 \mu \mathrm{m}$ in thickness and were deposited on fragments of a GaAs wafer. Hence, all the spectra are difference spectra.

Because of the non-polarity of all the bonds, no intense lines can be expected. To answer these questions, three windows are important: the uppermost region at $3000 \mathrm{~cm}^{-1}$ for the valence vibration of the $\mathrm{C}-\mathrm{H}$ bond $\left(v_{\mathrm{CH}}\right)$, the medium region at $1600 \mathrm{~cm}^{-1}$ for the valence vibration of the $C-C$ bond $\left(v_{C C}\right)$, and the lowermost region at $800 \mathrm{~cm}^{-1}$ for the deformation vibration of the $\mathrm{C}-\mathrm{C}$ bond $\left(\delta_{\mathrm{CC}}\right)$.

From these, the medium region does exhibit the most intense lines, and a positive proof can be drawn from the occurence of the vibrations in the region between 1650 and $1300 \mathrm{~cm}^{-1}$ (Figure 20). 


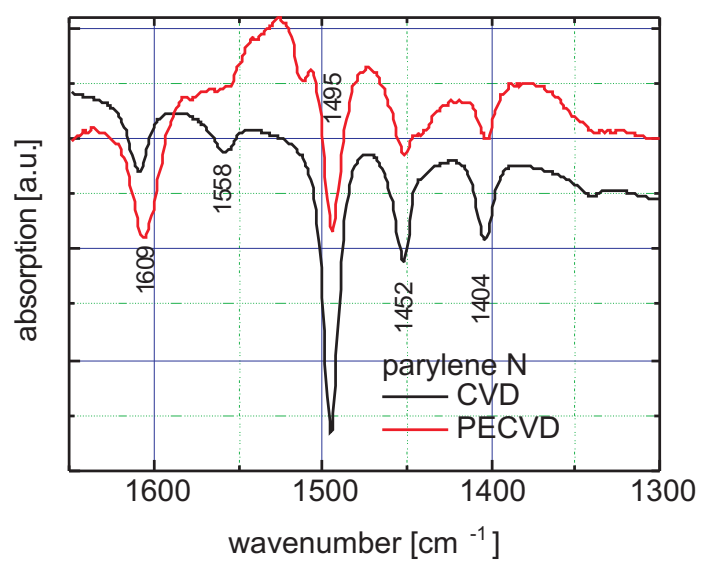

Figure 20. FTIR spectrum between 1650 and $1300 \mathrm{~cm}^{-1}$. Applied microwave power is $150 \mathrm{~W}$.

Both the layers show the deformation vibrations and ring vibrations $\left(\delta_{\mathrm{CH}_{2}}: 1404\right.$, $\left.\left.1452 \mathrm{~cm}^{-1}\right), v_{\text {ring: }}: 1495,1609 \mathrm{~cm}^{-1}\right)$. The line at $1558 \mathrm{~cm}^{-1}$ is due to $\mathrm{Cl}$-substitution and consequently do not occur in the $\mathrm{N}$-derivate.

This is a spectrum of a layer which has been deposited applying a microwave power of $150 \mathrm{~W}$ or a power density of $1.65 \mathrm{~W} / \mathrm{L}$. Beyond $175 \mathrm{~W}$ (or a power density of $1.9 \mathrm{~W} / \mathrm{L}$ ), no vibrations which are due to double bonds can be recorded. For safety reasons, the upper limit for microwave excitation had been fixed to $150 \mathrm{~W}$. Referring to Figure 16, layer growth is at its maximum.

The infrared transmission spectra of parylene $\mathrm{C}$ and parylene $\mathrm{N}$ are consistent with earlier works by Streitwieser and Ward, who pointed out that addition of an inert gas like Ar to a vapor of toluene, a derivate of benzene, leads to the microwave-induced generation of several several compounds in which the ring structure was still conserved [67]. However, they contradict the results of Olson, who investigated films deposited by conventional CVD [66], and also with those results which were obtained by radio-frequency generated plasma polymerization of styrene, by which the ring structure was destructed [68]. The reason for this different behavior which is reflected in surface properties (see below) is still an area of current research. Perhaps the molecules are subjected to the higher electromagnetic field and the static DC field across the hot electrode in RF discharges and are consequently destructed more readily than by microwave excitation $[69,70]$.

This is a very important result. Besides diamond whose purity can be qualified by Raman spectroscopy (only one line at $1332 \mathrm{~cm}^{-1}$ ), and CNTs which are characterized also by Raman spectroscopy, also low-power generated parylene can be qualified spectroscopically.

\subsubsection{Surface Properties}

Organic polymers exhibit an outstanding haptic feeling when touched. This is due to their negative surface energy. The investigation of these tribological properties (contact angle and the resulting surface energy) as function of pressure is completed by SEM micrographs and AFM graphs of the surface. The pressure was controlled downstream by a plate valve (VAT) at constant flow by evaporation of the dimeric species $\left(T_{\text {evap }}: 120^{\circ} \mathrm{C}\right.$, flow: $5.3 \mathrm{sccm}$ ) with some argon added (flow: $5 \mathrm{sccm}$ ) [56].

The contact angle has been measured using two different fluids [71]. To decide whether the application of a microwave plasma alone can open a window to new surface properties, which are distinguished from the thermally activated process, the $\mathrm{N}$-derivate was evaporated without any cracking procedure. The C-derivate, however, was exposed to both sources, the microwaves and temperature. Here are shown:

- parylene N: CVD and pure PECVD ( $P_{\mathrm{MW}}=125 \mathrm{~W}$ if not specified differently),

- parylene C: CVD and thermally assisted PECVD (75 W $\left.\leq P_{\mathrm{MW}} \leq 100 \mathrm{~W}\right)$.

Since the resulting properties for the two parylenes $\mathrm{C}$ and $\mathrm{N}$ are different, they are presented separately. 


\subsubsection{Parylene $\mathrm{N}$}

Contact Angle and Surface Energy

The behavior for the non-substituted species (CVD) shows the typical conduct which is expected for aromatic polymers: lipophilic character (very low angles against $\mathrm{CH}_{2} \mathrm{I}_{2}$ ) which is combined with extremely hydrophobic properties $\left(90^{\circ}\right.$, cf. Figure 21$)$.

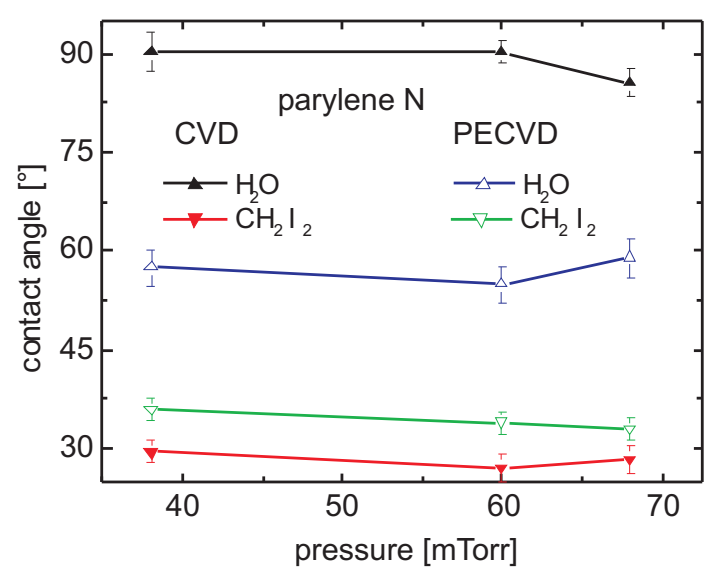

Figure 21. Contact angle as function of reactor pressure. Different shape of the contact angle for parylene $\mathrm{N}$ (CVD and PECVD). The CVD coating is significantly more hydrophobic than the PECVD one, but also more lipophilic.

The contact angle of the films does not exhibit any dependence on pressure, but support of microwaves assists in enlargening the hydrophilic character, leaving the lipophilic conduct almost unchanged. The AFM analysis reveals a medium-rough surface (Figure 22).

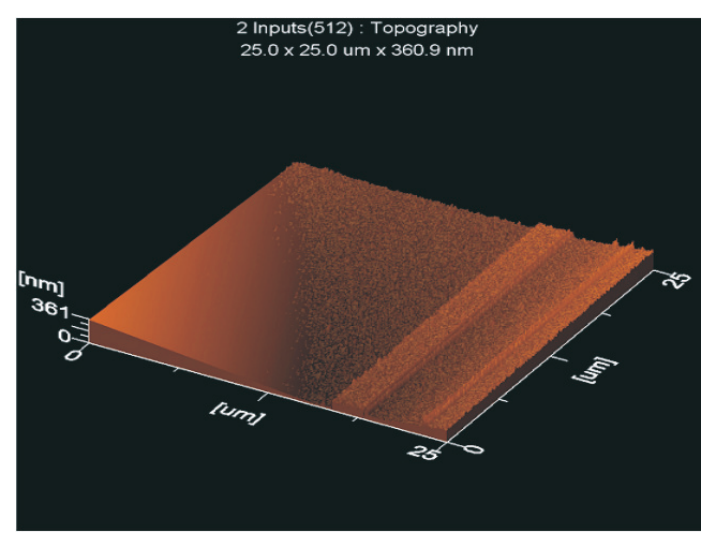

Figure 22. AFM micrograph of a CVD film of parylene N, deposited at $38 \mathrm{mTorr}$ (5 Pa), exhibiting a medium-rough surface.

Extending the experiment of determination the yield for both the processes CVD and PECVD (Figure 17) by enhancing the microwave power with a topmost level of $250 \mathrm{~W}$, the growth rate decreases after having reached a broad summit at approx. $125 \mathrm{~W}$ (Figure 16). At $250 \mathrm{~W}$, the growth is almost zero, which is accompanied by a linear decrease of the contact angles against water, i.e., the surface becomes more hydrophilic in character (Figure 23). 


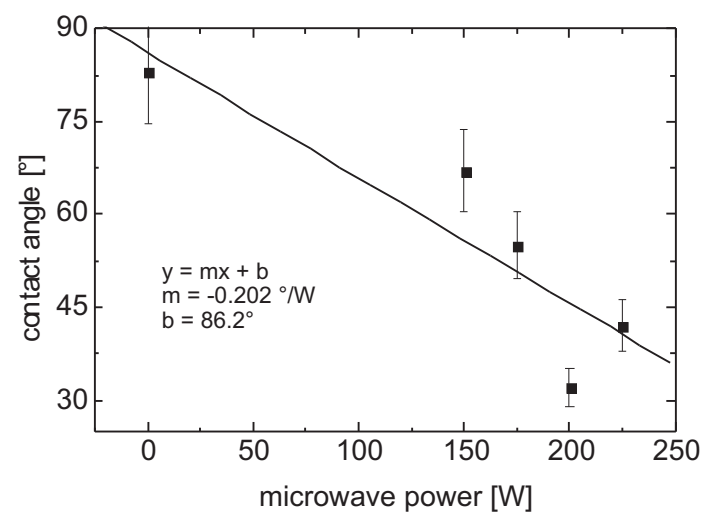

Figure 23. Contact angle of films of parylene $\mathrm{N}$ against water. With rising microwave power, the films become increasingly hydrophilic in character.

This behavior is inferred to the excitation by a plasma. However, it is not caused by the main component but by the residual gas $\mathrm{O}_{2}$, which will become obvious by the following discussion concerning the surface behavior.

\subsubsection{Parylene C}

\section{Contact Angle}

Coatings of parylene (CVD) are significantly more hydrophobic than deposits coated by PECVD, whereas the differences concerning the lipophilic character are not very distinct. So only for the CVD deposit, the contact angle is adjustable by the parameters gas flow and discharge pressure (shown here for the discharge pressure), Figure 24.

At the highest pressures, the contact angles are at their limits: at the lower level (lipophilic behavior), the angle is extremely flat, whereas at the upper limit (hydrophobic behavior), the water droplet is compressed by its own weight.

\section{Surface Tension}

The surface energy of the CVD polymers can be varied across a large range: with growing pressures, the surface tension will increase by almost 50\% for the plain CVD (Figure 25). This does not hold true for the plasma enhanced variation. In contrast to this method, the surface energy remains remarkably constant over the covered pressure range. The split into the polar and dispersive fraction does show some movement at higher discharge pressures, but they are contradictory which cancel each other. Rising contact angles against $\mathrm{CH}_{2} \mathrm{I}_{2}$ leads to falling surface energies.
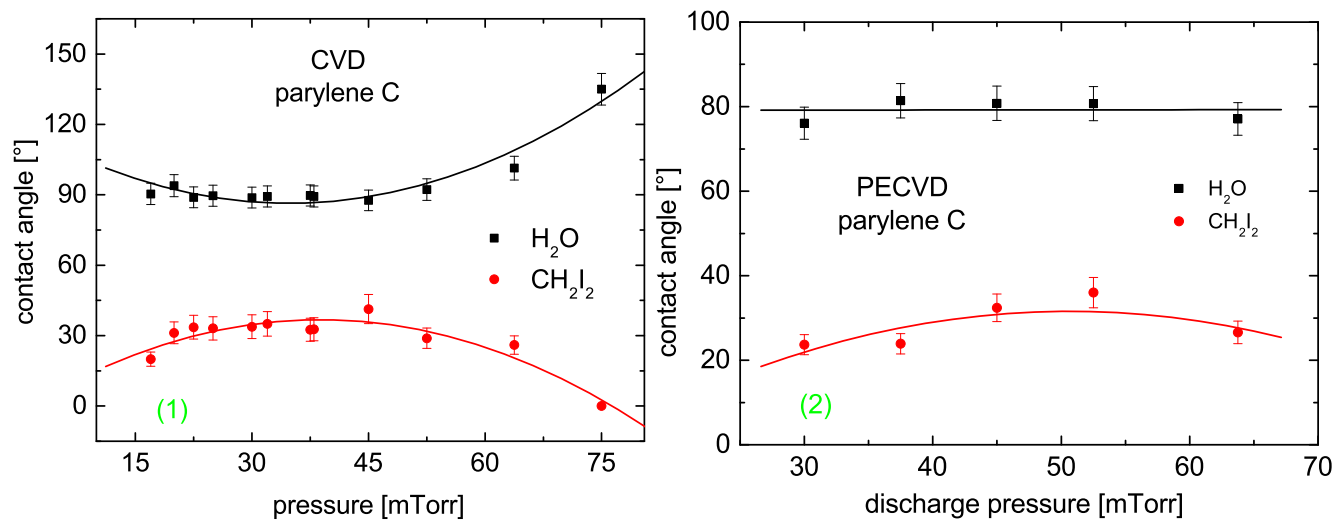

Figure 24. Different shape of the contact angle for CVD parylene C (1) and PECVD parylene C (2). CVD parylene is significantly more hydrophobic than PECVD parylene. 

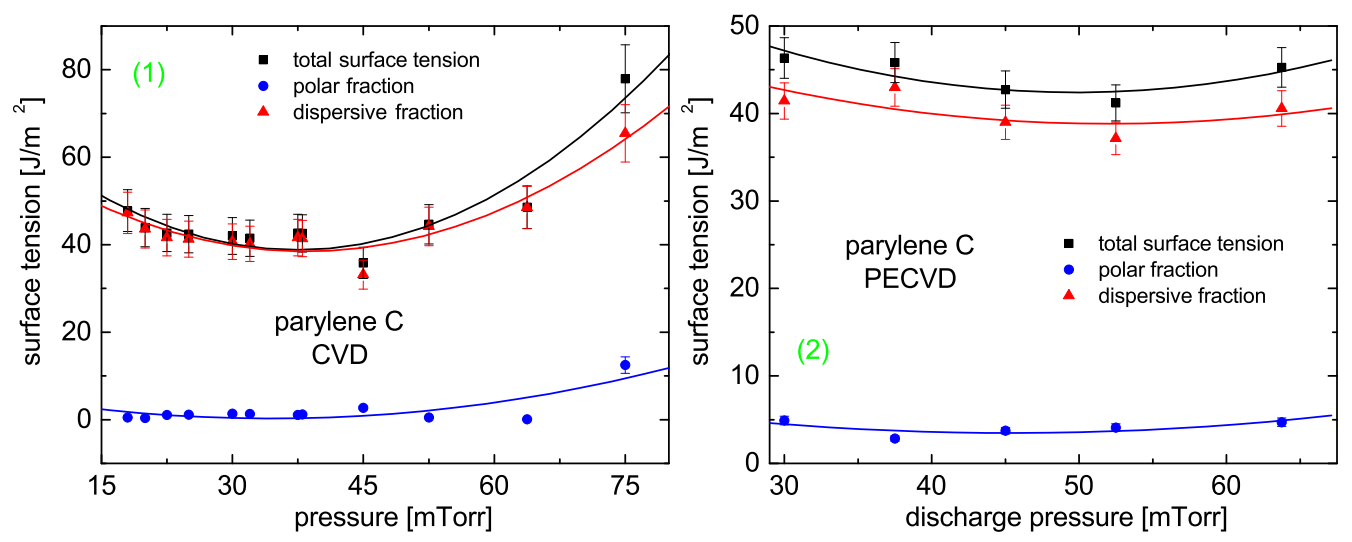

Figure 25. Different shape of the surface tension of CVD parylene $C$ (1) and PECVD parylene C (2). Microwave power was between 75 and $100 \mathrm{~W}\left(0.9 \mathrm{~W} / \mathrm{L}\right.$ and $1.1 \mathrm{~W} / \mathrm{L}, n_{\mathrm{p}}$ between $6 \times 10^{8} / \mathrm{cm}^{3}$ and $\left.1 \times 10^{10} / \mathrm{cm}^{3}[4]\right)$.

\subsection{Surface Behavior}

In conclusion, there are at least two main reasons which can influence the behavior of surfaces against water, a chemically based cause (hydrophilic groups) and a physically based one (surface roughness).

\subsubsection{Incorporation of Hydrophilic Groups}

For an end vacuum of $0.5 \mathrm{mTorr}(1 / 10 \mathrm{~Pa})$, the number density of residual oxygen is $1.7 \times 10^{13} / \mathrm{cm}^{3}$. For a "normal" process $\left(T_{\text {evap }}=130^{\circ} \mathrm{C}\right)$, the evaporation rate is $9 \mathrm{sccm}$ in our large reactor (volume: $90 \mathrm{~L}$ ), after the thermal cleavage, it doubles its value to $18 \mathrm{sccm}$. Argon is added to dilute the vapor. In the equimolar case, the pumping speed is approximately constant at $2.4 \mathrm{~L} / \mathrm{s}$. Hence, the number density of the monomers is $3.7 \times 10^{15} / \mathrm{cm}^{3}$, which results in a ratio of monomers to oxygen molecules of only 220 . For comparison, if $\mathrm{Al}$ is being sputtered reactively in an ambient doped with $\mathrm{O}_{2}$ at a typical deposition rate of $1 \mu \mathrm{m} / \mathrm{min}$, a partial pressure of just $0.5 \mathrm{mPa}\left(5 \times 10^{-6}\right.$ Torr $)$ is sufficient for complete oxidation (56 atomic percent of oxygen). Using the equation connecting current density to drift velocity $j=\rho \times v$ to estimate the density of the Al atoms located between the electrodes, it is evident that termination will most likely occur by oxygen capture. In the case that $E_{\text {kin }}$ equals $4 \mathrm{eV}$, the initial velocity of the $\mathrm{Al}$ atoms is approximately $28 \sqrt{\frac{4}{3}}=33 \times 10^{5} \mathrm{~cm} / \mathrm{s}$. If the energy is reduced to $1 \mathrm{eV}$ when the atom hits the surface, the velocity still remains at $2 \times 10^{5} \mathrm{~cm} / \mathrm{s}$. With an area of $8 \AA^{2}$ required for one $\mathrm{Al}$ atom, a flux of $8 \times 10^{16}$ atoms $/ \mathrm{cm}^{2} \mathrm{~s}$ results, which translates to a density of $11 \times 10^{11}$ atoms $/ \mathrm{cm}^{3}$. The partial pressure of oxygen is lower by only one order of magnitude $\left(1.6 \times 10^{11}\right.$ atoms $\left./ \mathrm{cm}^{3}\right)$ !

This termination reaction undoubtedly causes a reduction in chain length and a switch to the hydrophilicity, because oxygen will form $\mathrm{CH}(\mathrm{OH})$ - and $\mathrm{C}=\mathrm{O}$-groups.

In every case, the residual gas vacuum is of the order of $1 \mathrm{~Pa}(7.5 \mathrm{mTorr})$, which is the lower vacuum limit for conventional rotary vane pumps. This residual vacuum means that the residual gas pressure of oxygen is on the order of 2 mTorr, and the $\mathrm{O}_{2}$ diradical easily terminates the polymeric reaction via Equation (22):<smiles>Cc1ccc(CC#CCc2ccc(COO)cc2)cc1</smiles>

or through other termination reactions. This behavior may influence the degree of polymerization (dispersity or chain length) and eventually influence the film density, thus resulting in inhomogeneous layers. 


\subsubsection{Surface Roughness}

From the equations of Wenzel [72], it is obvious that the conduct of a surface against polar and unpolar solvents (i.e., hydrophilicity and hydrophobicity) is amplified by its roughness. For very rough surfaces, the application of the Cassie equation reveals that even hydrophilic surfaces can be transformed to hydrophobic surfaces [73].

We addressed this field by comparing the surface roughness as function of total pressure for the two excitation methods thermal and plasma dissociation. At low pressure (22 mTorr), the micrographs of parylene $C$ exhibit some details of a very smooth pinhole free surface, irrespective of whether the deposition method has been simple CVD or PECVD (Figure 26).

As AFM measurements reveal (Figure 27), the surface roughness depends strongly on the deposition method. For both derivates, the PECVD film is definitely smoother than the CVD film, where this ratio is higher for parylene $\mathrm{N}$. This roughness determines the hydrophobic conduct of the films to a higher extent than the lipophilic behavior which behave almost identical. For parylene $C$, the difference is not as distinct, which is reflected in the contact angles. According to the Wenzel equation, a rougher surface is connected with poorer wettability (Lotos effect) [72].

Both these effects,

- polar groups which terminate the chains at the surface, and

- the smoother surfaces of PECVD layers,

cause better wettability against water. The increasing roughness with rising pressure, which is explicitely depicted in Figures 22 and 27 for CVD parylene $\mathrm{N}$ is referred to the higher density of monomers in the vapor; this leads to a higher extent of volume polymerization. Consequently, a lower partial pressure of monomers (at same total pressure) would cause smoother surfaces. This is shown in Figures 28 and 29, where AFM micrographs of parylene $\mathrm{N}$ are shown which have been obtained from surfaces deposited at three different degrees of solution (with argon). They have been evaluated applying the program GWYDDION (version 2.32). At same partial pressure of the monomer (6 mTorr), the average roughness decreases with increasing dilution, but at the cost of a lower growth rate (Figure 14.1,2).
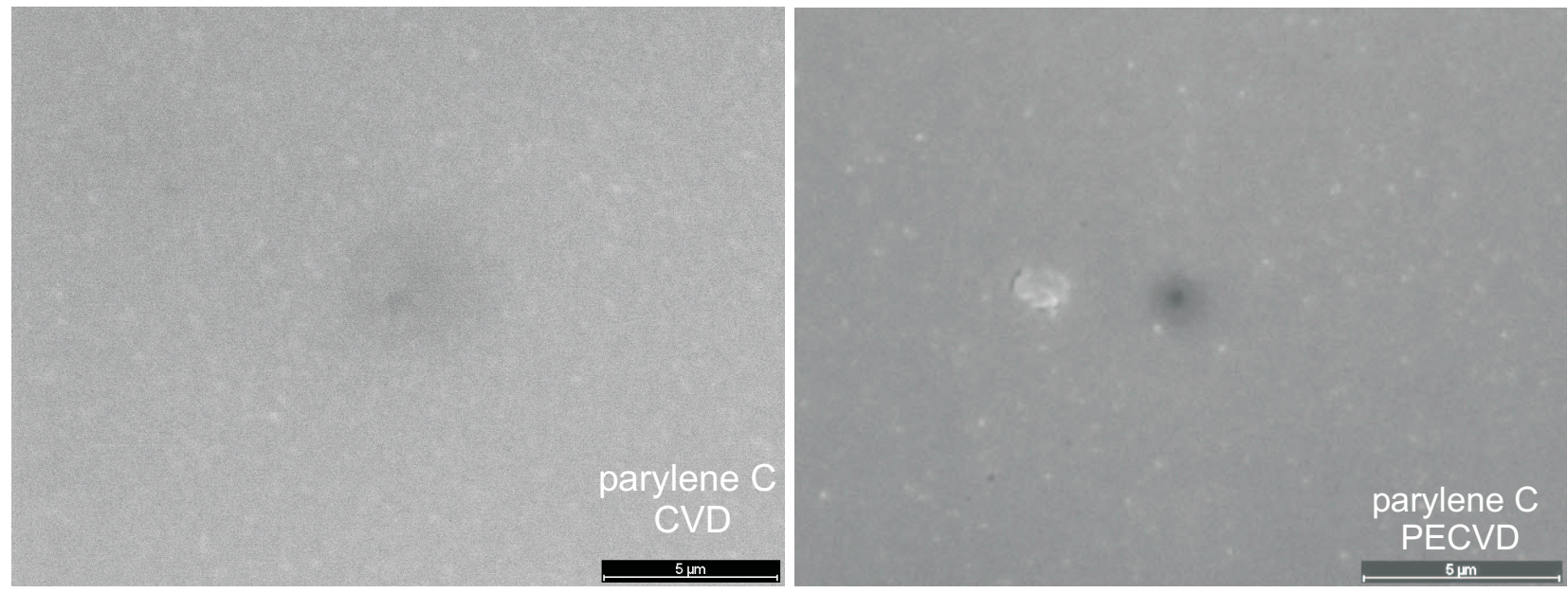

Figure 26. Micrographs of parylene $\mathrm{C}$ (CVD, LHS) and parylene $\mathrm{C}$ (PECVD, RHS), scaling bar is $5 \mu \mathrm{m}$.

The surface energy of the films of the $\mathrm{N}$-derivate is at the low-pressure limit of the chlorine-derivate. Other groups report contact angles against water of $90-103^{\circ}$ for parylene $C[17,74-77]$ and $81-87^{\circ}$ for parylene $\mathrm{N}$, resp. $[77,78]$. So their windows are very narrow compared to the widths obtained in this study.

Over the whole range investigated, the layers behave hydrophobic in character with only slight deviations. The hydrophilic behavior can be significantly influenced by a plasma attack which generates not only surfaces with a finer grain size but also give rise 
for the formation of terminal bonds hydrophilic in character, e.g., $\mathrm{C}-\mathrm{OH}$ or $\mathrm{C}-\mathrm{NH}_{2}$ groups which replace a $\mathrm{C}-\mathrm{H}$ bond in the thread molecule, or a $\mathrm{C}=\mathrm{O}$ bond replacing a $\mathrm{CH}_{2}$ group. These bonds are homogeneously distributed in the bulk of the layer.
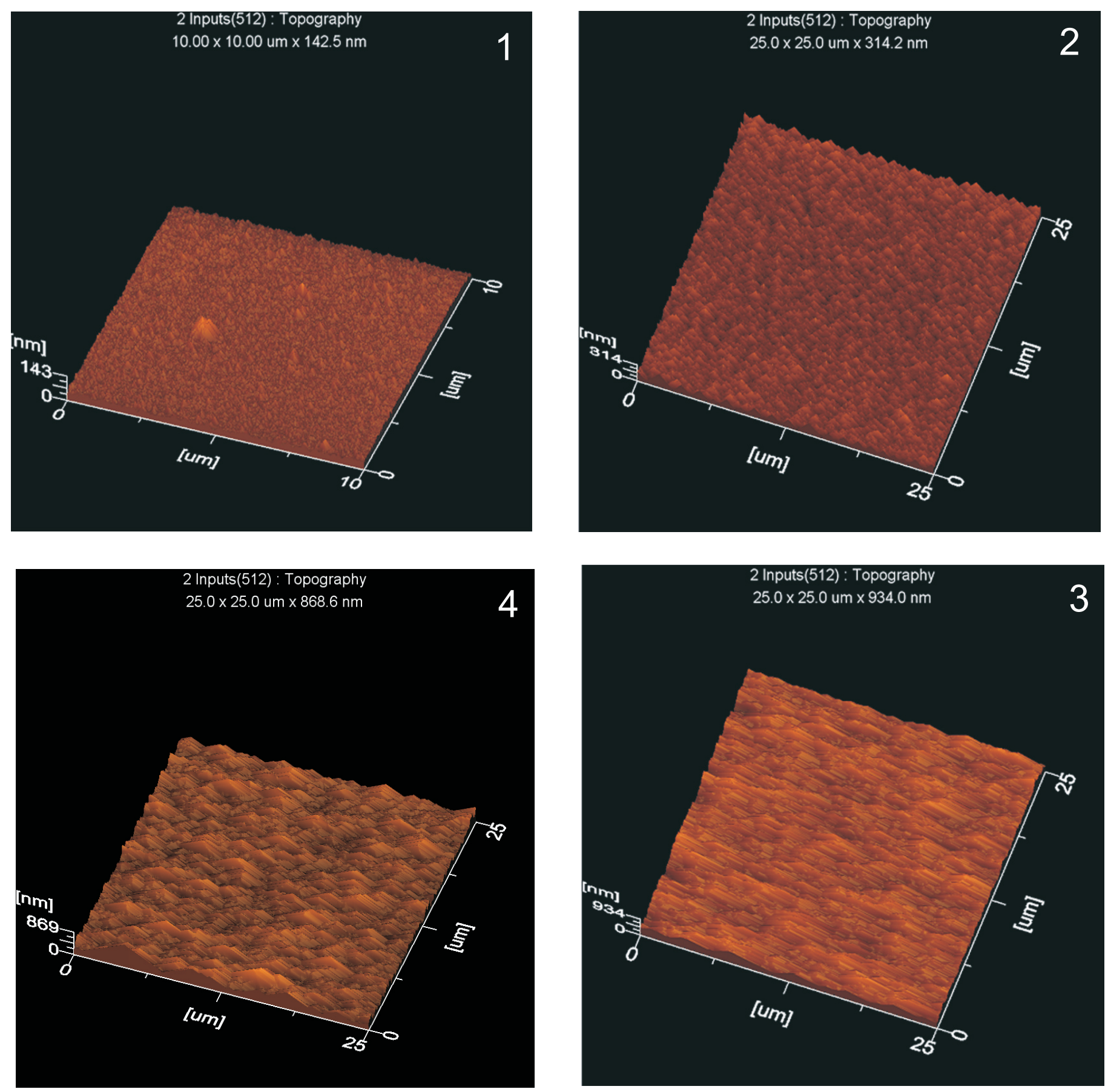

Figure 27. AFM measurements of surfaces smooth and rough in character. Smoothening enhances the wettability, operating pressure: 60 mTorr $(8 \mathrm{~Pa}) .(\mathbf{1}, \mathbf{4})$ : parylene N, (2,3): parylene C. Top: PECVD with smooth surfaces, bottom: CVD with rough surfaces. 


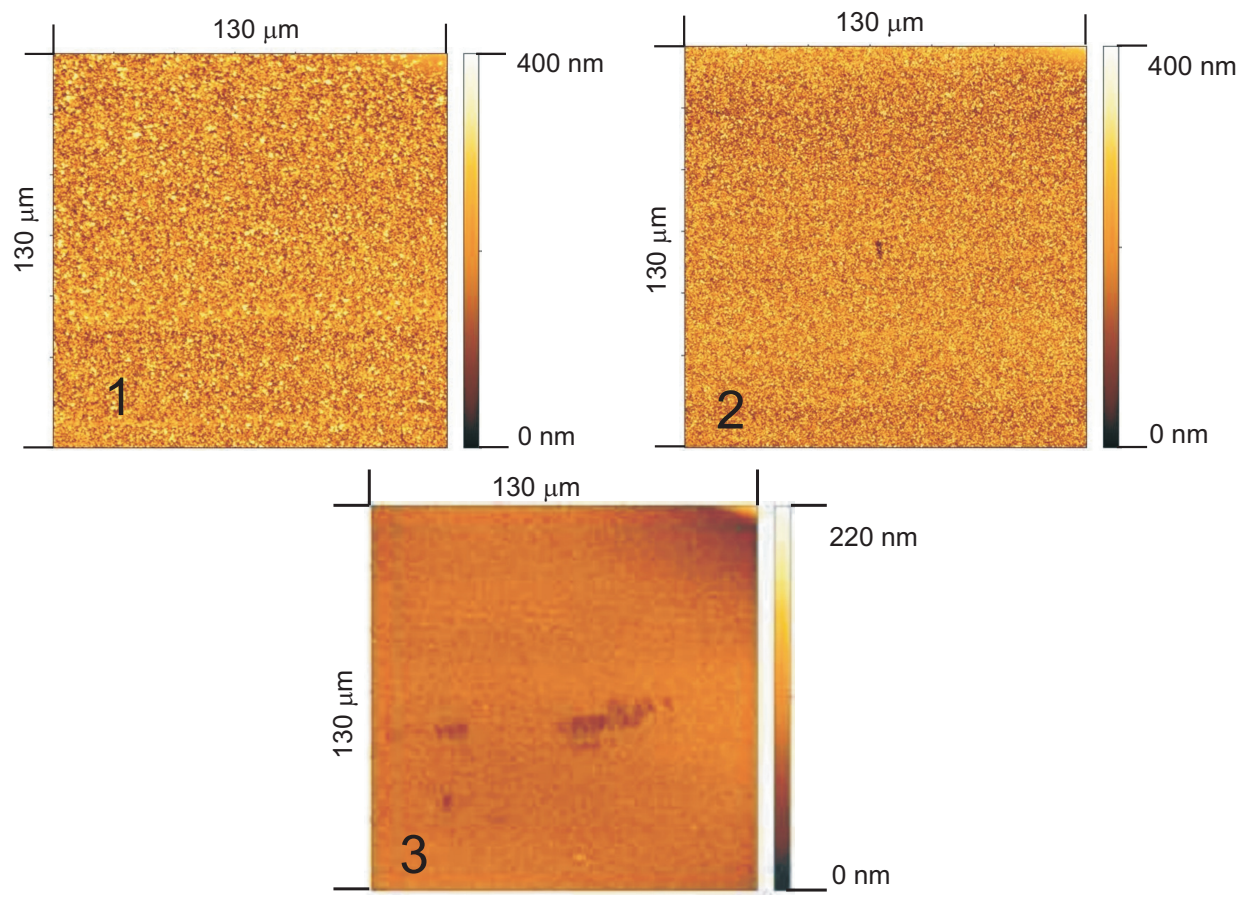

Figure 28. AFM measurements of layers which have been deposited with same partial pressure of p-xylylene $\mathrm{N}$, but different dilution with argon. (1): pure (6 mTorr, 0.8 Pa), (2): $37.5 \mathrm{mTorr}$ (5 Pa), (3): $75 \mathrm{mTorr}(10 \mathrm{~Pa})$.

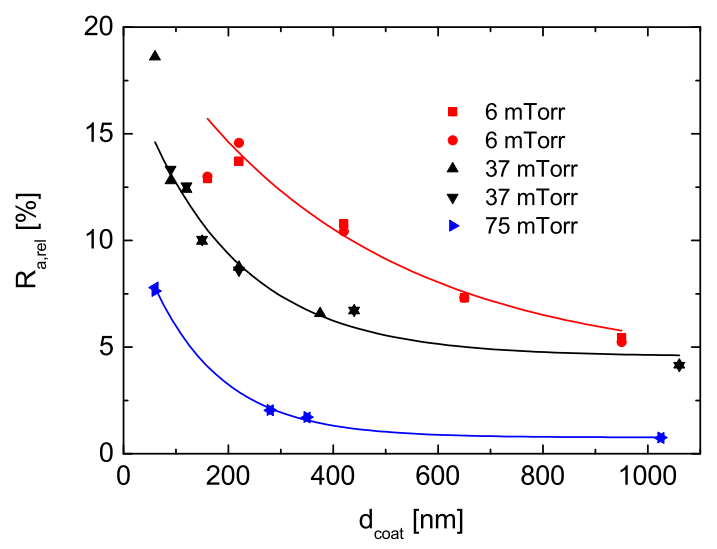

Figure 29. Relative roughness (hole depth $\div$ layer thickness as function of absolute layer thickness) for three different pressures (parylene N). 6 mTorr is the pure ambient, the higher pressures are caused by dilution with argon.

\subsection{Functionalization of Surfaces}

The films deposited from an ambient consisting of the pure ambient or the pure ambient diluted with argon remain hydrophobic [79]. One method to switch the functionality to hydrophilic behavior can easily be performed by a plasma treatment with oxygen [80]. As shown in Figure 30, where the change of the film quality is depicted as function of time of plasma treatment, this surface activation (replacement of hydrophobic $\mathrm{C}-\mathrm{H}$ bonds by hydrophilic $\mathrm{C}-\mathrm{OH}$ bonds) leads to contact angles against water down to $30^{\circ}$, but at the expense of layer thickness.

Further increase is correlated with longer times of treatment; eventually, this process leads to the starting values when the layer has been completely etched away. After three weeks of storage, values increase slightly, but the general tendency towards hydrophilicity does not turn back. The rising hydrophilic character can be referred to the congruent slope of the polar fraction of the surface tension (Figure 31). 

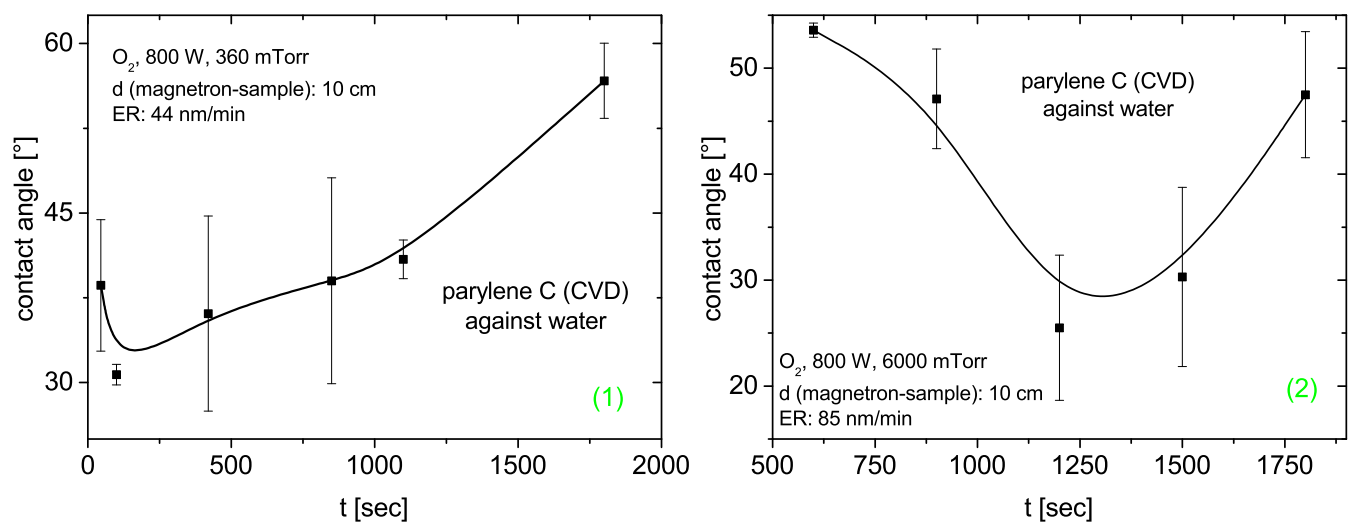

Figure 30. Contact angle of parylene $C$ layers deposited with CVD and subsequent oxygen treatment using two different discharge pressures. (1): 360 mTorr, (2): 6000 mTorr. The conduct against water is completely altered.

This conduct has been communicated also by Olson [66], who observed the same phenomenon also for exposing the parylene film to a plasma of the inert gas argon, and a retreat of hydrophilicity after about one day. Bi et al. report on perfect wetting after exposure to an $\mathrm{O}_{2}-\mathrm{RF}$ plasma [81]. Tsougeni et al. applied an $\mathrm{O}_{2}$ plasma to increase the hydrophilicity of polymethacrylates [82]. However, the original value was never reached. The trend to hydrophilicity for PECVD generated films and this hydrophilization are caused by the same source, namely oxygen, however, in the first case unintended.

A second way is the copolymerization with oxygen. As shown in Figure 32, for both the excitation techniques, a change in surface conduct is feasible. However, the values for hydrophilic behavior as measured by the drop pendant method are significantly better (lower) for plasma excitation than for the thermal variant. The values reach flat values almost of $20^{\circ}$.

This track of oxygen treatment has successfully applied in our long-lasting project to develop biocompatible antibacterial ureteral stents [83-85]. As result of the experiments described in this last section, we could switch a hydrophobic surface of parylene into a hydrophilic surface within $15 \mathrm{~s}$ by application of a mild microwave-driven plasma.
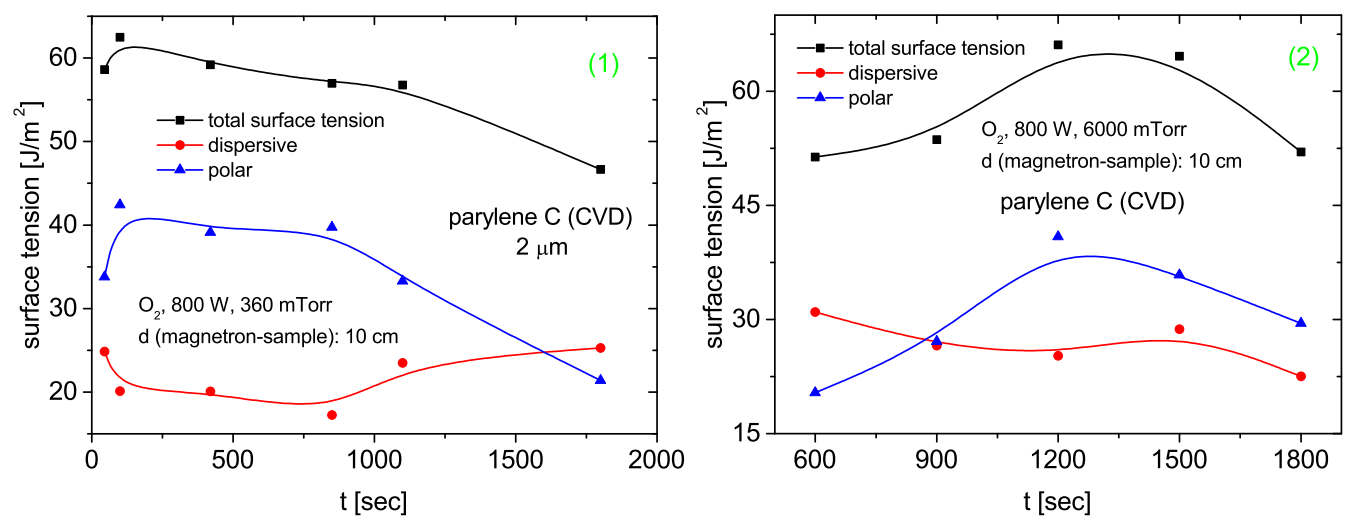

Figure 31. Surface energy of parylene $C$ layers deposited with CVD and subsequent oxygen plasma treatment for two different discharge pressures. (1): 360 mTorr, (2): 6000 mTorr. The conduct against water is completely altered. 

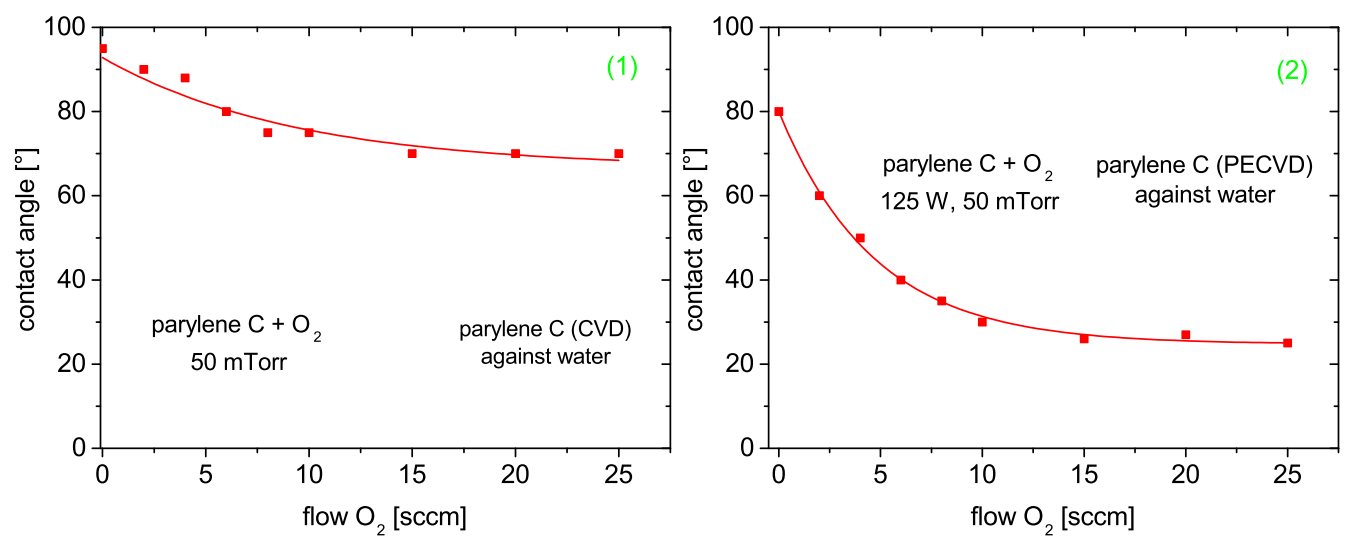

Figure 32. Contact angle of parylene $C$ layers codeposited with oxygen with CVD (1) and PECVD (2). The tendency towards hydrophilicity is obvious.

\subsubsection{Parylene, Copolymerized with $\mathrm{Cf}_{4}$}

Contact Angle and Surface Energy

Doping the atmosphere with $\mathrm{CF}_{4}$ leads in both cases to the expected increase in hydrophobic character. As shown in Figure 33, the investigated flow range covers more than double the flow of mono- $p$-xylylene (flow is $8.1 \mathrm{sccm}$ ).

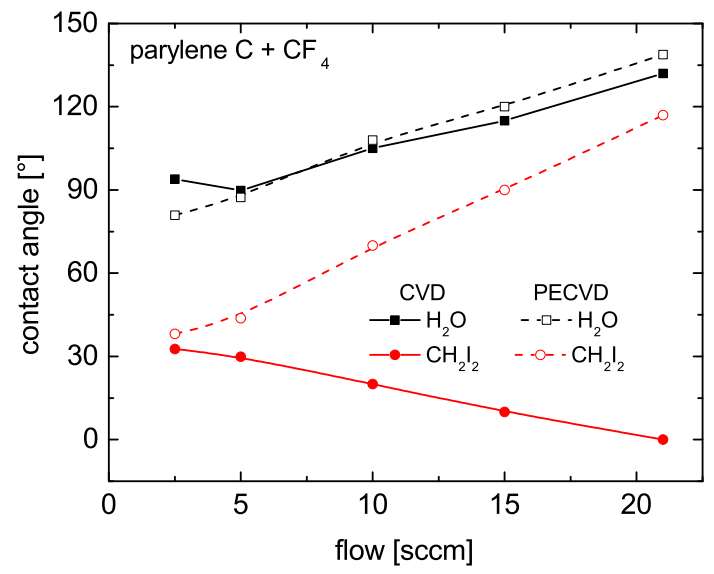

Figure 33. Doping of the atmosphere of mono- $p$-xylylene $\mathrm{C}(\mathrm{MPX}-\mathrm{C})$ with $\mathrm{CF}_{4}$ leads to increasing hydrophobic behavior.

Whereas for the CVD layers, the character still remains lipophilic, the plasma-generated film just exhibits an opposite conduct with almost inverted slope. As can be drawn from the evaluation of the surface energy (Figure 34), this is nearly completely due to a large increase of the dispersive fraction in the CVD case which is opposed by a steep drop in the case of PECVD, whereas the polar fraction remains almost constant in both cases. 

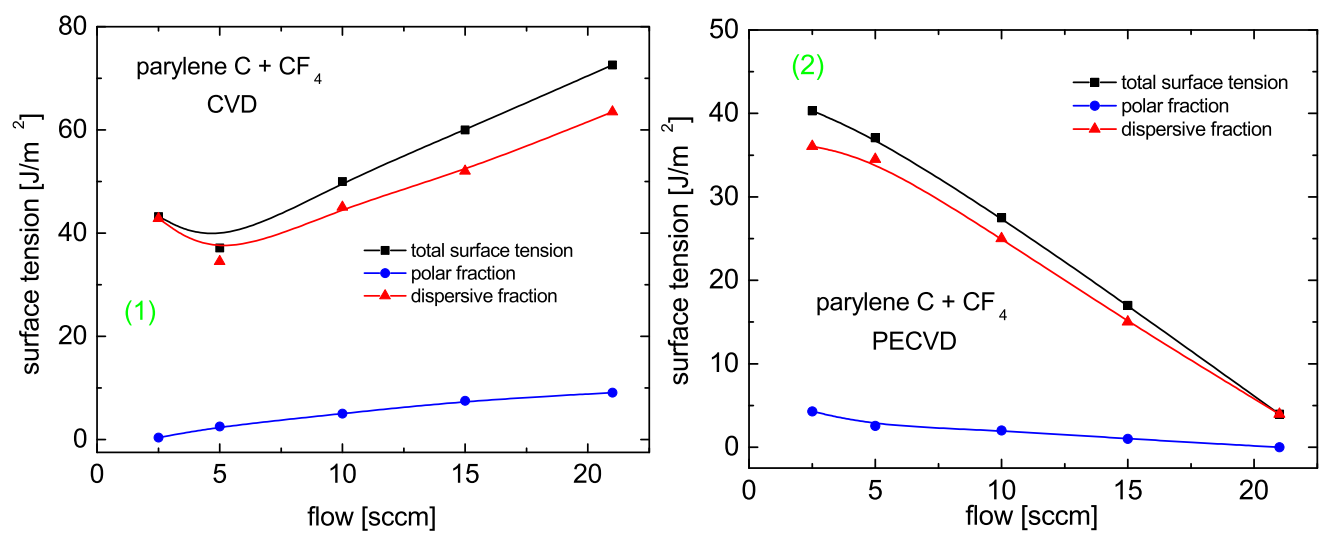

Figure 34. Different habits of the surface tension of CVD parylene C (1) and PECVD parylene C (2), doped with $\mathrm{CF}_{4}$. Microwave power was between 100 and $125 \mathrm{~W}$.

SEM

This super-fluidic behavior has been found to be caused most frequently by a surface which exhibits a roughness in the nano-range [86,87]. This can be referred to two main reasons: At high flow rates of the monomeric species, volume polymerization can favor opaque layers. For high powers, fragmentation dominates polymerization, and this also results in opaque layers. In contrast to this observation, the plasma-deposited layers exhibit a relatively smooth surface, and the super-fluidity cannot be referred to the common Lotos effect (Figure 35).

This behavior resembles the observations made by Bi et al. [81], who found that after exposing polyparylene $\mathrm{C}$ to an $\mathrm{SF}_{6}$ plasma, the surface morphology did not change that much, instead, they found a fluor peak in the Auger spectrum. From a chemical point of view, it is not intelligible why the difference between $-\mathrm{OH}$ and $-\mathrm{F}$ as terminating group makes any difference.

The standard deposition process yields hydrophobic layers. With the two exceptional dopants oxygen and tetrafluoromethane, the behavior can be influenced manifoldly by dopants: $\mathrm{O}_{2}$ switches to hydrophilic behavior, with $\mathrm{CF}_{4}$, volume polymerization in the CVD case leading to roughened surfaces turns to micro-roughened surfaces in the PECVD case with superhydrophobic character-at same flow of $\mathrm{CF}_{4}$. This roughness is supposed a requirement for this effect according to model calculations by Kim and Choi [88].
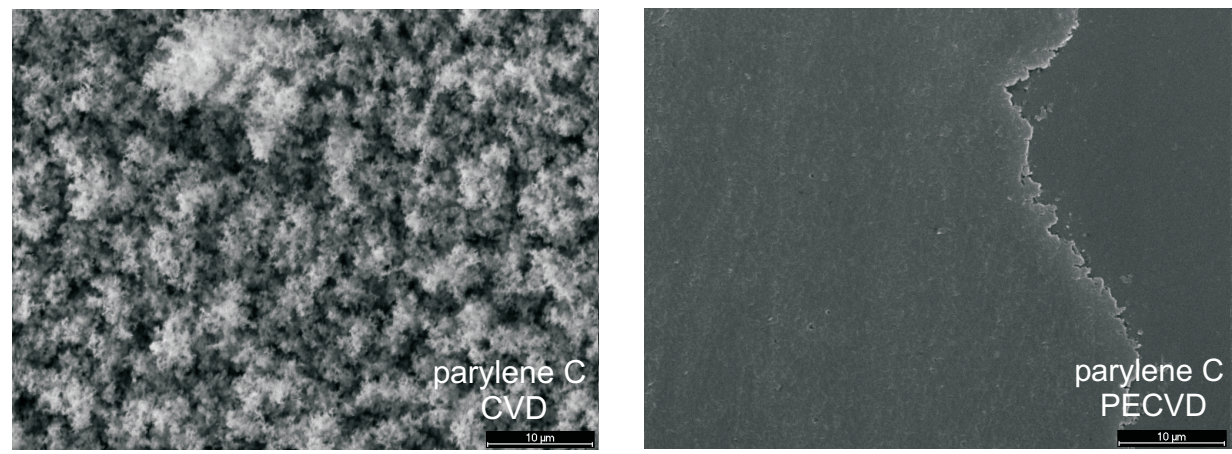

Figure 35. SEM of parylene $\mathrm{C}$, copolymerized with $\mathrm{CF}_{4}$ : $\mathrm{CVD}$ generates rough a surface in a microscopic scale (LHS, scaling bar is $10 \mu \mathrm{m}$ ). Microscopic dust particles in the ambient were incorporated during the coating process resulting in an opaque layer (volume polymerization). PECVD layers remain their transparency and exhibit a super-fluidic performance (RHS, scaling bar is $10 \mu \mathrm{m})$.

In contrast to the findings of Rioboo et al. who found a relatively sharp transition in polypropylene which is blended with three different additives (among them is styrene), the observed transition is relatively smooth and broad [89]. 


\section{Conclusions}

The double radicalic function of the xylylene monomer is stabilized by the aromatic ring structure. This favors the growth of long one-dimensional chains. Deposited in an atmosphere with a diluent gas, very fine grain size deposits are possible, whereas a deposition out of the pure vapor favors larger grains. This behavior indicates a change from volume polymerization with the generation of flakes or grains to surface polymerization similar to the change from common CVD to epitaxial processes. Parylene exhibits excellent properties in the bulk (dielectric strength, low permeability against gases and liquids), and its surface conduct against liquids can be influenced by the deposition method, by adding dopants to the atmosphere, or by post-deposition treatment. Only $15 \mathrm{~s}$ of a mild oxygen plasma is sufficient to switch from hydrophobic to hydrophilic character.

\section{Outlook}

Plasma enhanced chemical vapor deposition of organic compounds is a promising technology to get access to new polymolecules as diamonds and carbon nano tubes. Although Cullinan I and Cullinan 2 are bigger than the human-produced diamonds, their purity lacks the standard of PECVD. With CNTs, a new class of graphenes (also found in nature as graphite) has come into focus-a system whose properties can be tailor-made and often surpass qualities which are known of conventional materials. The purity against contaminants and also the degree of uniform bonding character can be checked by Raman spectroscopy.

Applying PECVD to saturated carbon compounds opens a new window to a new class of compound layers. With thermal methods, it is simply impossible to obtain a layer with reproducible properties. In contrast to the aforementioned species, purity cannot be expected because electrons will strip not only hydrogen atoms from the carbon frame but will also fragment the frame itself. Therefore, a simple hydrocarbon structure which is built of just primary carbon atoms forming a $\mathrm{CH}_{2}$ chain with two terminal $\mathrm{CH}_{3}$ groups will end also with secondary $\mathrm{C}_{2} \mathrm{CH}$ and even tertiary $\mathrm{C}_{3} \mathrm{C}$ atoms. With heteroatoms in the initial compound, the variety of possible reactions will grow explosively - well-known to every organic chemist.

The lack of analytical methods to evaluate the quality of these films explains the ressentiments of a great part of scientists against PECVD of organic layers. On the other hand, surfaces have easily come into reach which exhibit extraordinary qualities as the phenomenon of superhydrophobicity - at low cost and with a minimum of environmental issues. The conduct of surfaces can easily be switched from hydrophobic to hydrophilic, temporary or permanent. These possibilities have been extensively explicated using the molecule $p$-xylylene which has evolved a molecule with an extreme range of applications.

When discussing organic reactions, it should always be kept in mind that on both tracks (CVD and PECVD), only one reaction path is seldom (or never) followed.

Funding: This research received no external funding.

Acknowledgments: It is a pleasure for me to thank Jim Wang who gave me intensive editorial support during the last year and eventually launched the manuscript into the editing process which has been successfully finished by Liz Yang.

Conflicts of Interest: The author declares no conflict of interest.

\section{References}

1. Davey, J.E.; Pankey, T. Epitaxial GaAs Films Deposited by Vacuum Evaporation. J. Appl. Phys. 1968, 39, 1941-1948. [CrossRef]

2. Cho, A.Y.; Arthur, J.R., Jr. Molecular Beam Epitaxy. Prog. Solid State Chem. 1975, 10, 157-192. [CrossRef]

3. Gorham, W.F. Para-Xylylene Polymers. U.S. Patent 3,342,754, 19 September 1967.

4. Franz, G.; Rauter, F.; Dribinskiy, S.F. Characterization of microwave plasmas for deposition of polyparylene. J. Vac. Sci. Technol. 2009, A27, 1035. [CrossRef]

5. Schäfer, H. Chemical Transport Reactions; Academic Press: New York, NY, USA; London, UK, 1964. 
6. Ganguli, S.; Agrawal, H.; Wang, B.; McDonald, J.F.; Lu, T.-M.; Yang, G.-R.; Gill, W.N. Improved growth and thermal stability of parylene films. J. Vac. Sci. Technol. 1997, A15, 3138-3142. [CrossRef]

7. Errede, L.A.; Hoyt, J.M. The Chemistry of Xylylenes. III. Some Reactions of p-Xylylene that Occur by Free Radical Intermediates. J. Am. Chem. Soc. 1960, 82, 436-439. [CrossRef]

8. Errede, L.A.; Gregorian, R.S.; Hoyt, J.M. The Chemistry of Xylylenes. VI. The Polymerization of p-Xylylene. J. Amer. Chem. Soc. 1960, 82, 5218-5223. [CrossRef]

9. Kramer, P.; Sharma, A.K.; Hennecke, E.E.; Yasuda, H. Polymerization of Para-Xylylene Derivatives Parylene Polymerization. I. Deposition Kinetics for Parylene N and Parylene C. J. Polym. Sci. 1984, 22, 475-491. [CrossRef]

10. Yasuda, H.K.; Yeh, Y.S.; Fusselman, S. A growth mechanism for the vacuum deposition of polymeric materials. Pure Appl. Chem. 1990, 62, 1689-1698. [CrossRef]

11. Boehm, G.; Katz, G.S.; Meyer, R.; Amann, M.-C. AlInAs-GaInAs strain-compensated active regions for injectorless quantum cascade lasers. J. Cryst. Growth 2008, 311, 1932-1934. [CrossRef]

12. Schamberger, F.; Ziegler, A.; Franz, G. Influence of film thickness and deposition rate on surface quality of polyparylene coatings. J. Vac. Sci. Technol. 2012, B30, 051801. [CrossRef]

13. Franz, G. Low Pressure Plasmas and Microstructuring Technology; Springer: Berlin/Heidelberg, Germany, 2009 ; Chapter 8.

14. Franz, G. Low Pressure Plasmas and Microstructuring Technology; Springer: Berlin/Heidelberg, Germany, 2009 ; Chapters 5 and 6.

15. Lieberman, M.A.; Lichtenberg, A.J. Principles of Plasma Discharges and Materials Processing, 1st ed.; Wiley: New York, NY, USA, 1994; pp. 301-326.

16. Bogart, K.H.A.; Dalleska, N.F.; Bogart, G.R.; Fisher, E.R. Plasma enhanced chemical vapor deposition of $\mathrm{SiO}_{2}$ using novel alkoxysilane precursors. J. Vac. Sci. Technol. 1995, A13, 476-480. [CrossRef]

17. Coburn, J.W.; Kay, E. Some Chemical Aspects of the Fluorocarbon Plasma Etching of Silicon and Its Compounds. IBM J. Res. Develop. 1979, 23, 33-41. [CrossRef]

18. Coburn, J.W.; Winters, H.F. Plasma Etching-A Discussion of Mechanisms. J. Vac. Sci. Technol. 1979, 16, 391-403. [CrossRef]

19. Franz, G. Low Pressure Plasmas and Microstructuring Technology; Springer: Berlin/Heidelberg, Germany, 2009 ; Chapter 7.

20. Franz, G. Low Pressure Plasmas and Microstructuring Technology; Springer: Berlin/Heidelberg, Germany, 2009 ; Chapters 3 and 9.

21. Dorai, R.; Kushner, M.J. A model for plasma modification of polypropylene using atmospheric pressure discharges. J. Phys. D Appl. Phys. 2003, 36, 666-685. [CrossRef]

22. Yasuda, H.; Hirotsu, T. Critical Evaluation of Conditions of Plasma Polymerization. J. Polym. Sci. 1978, 16, 743-759. [CrossRef]

23. Yasuda, H. Plasma Polymerization; Academic Press: Orlando, FL, USA, 1985.

24. Koch, R. The intrinsic stress of poylcrysatlline and epitaxial thin metal films. J. Phys. Condens. Matter 1994, 6, 9519-9550. [CrossRef]

25. Koch, R. Stress in Evaporated and Sputtered Thin Films-A Comparison. Surf. Coat. Technol. 2010, 204, 1973-1982. [CrossRef]

26. Klemberg-Sapieha, J.E.; Martinu, L.; Wertheimer, M.R.; Günther, P.; Schellin, R.; Thielemann, C.; Sessler, G.M. Plasma deposition of low-stress electret films for electroacoustic and solar cell application. J. Vac. Sci. Technol. 1996, A14, 2775-2779. [CrossRef]

27. Whitfield, R.; Parkatzidis, K.; Truong, N.P.; Junkers, T.; Anastasaki, A. Tailoring Polymer Dispersity by RAFT Polymerization: A Versatile Approach. Chem 2020, 6, 1340-1352. [CrossRef]

28. Jensen, R.J.; Bell, A.T.; Soong, D.S. Plasma Polymerization of Ethane. I. Experimental Studies of Effluent Gas Composition and Polymer Deposition Rates. Plasma Chem. Plasma Process. 1983, 3, 139-161. [CrossRef]

29. Jensen, R.J.; Bell, A.T.; Soong, D.S. Plasma Polymerization of Ethane. II. Theoretical Analysis of Effluent Gas Composition and Polymer Deposition Rates. Plasma Chem. Plasma Process. 1983, 3, 163-192. [CrossRef]

30. Aisenberg, S.; Chabot, R.W. Physics of Ion Plating and Ion Beam Deposition. J. Vac. Sci. Technol. 1973, 10, 104-107. [CrossRef]

31. Spitsyn, B.V.; Buyilov, L.L.; Derjaguin, B.V. Vapor Growth of Diamond on Diamond and other Surfaces. J. Cryst. Growth 1981, 52, 219-226. [CrossRef]

32. Bachmann, P.K. Diamond thin film technology I. Diamond deposition. Adv. Mater. 1990, 2, 195-199. [CrossRef]

33. Awakowicz, P. Niederdruckplasmen: Modelle, Diagnostikmethoden und Anwendungen. Habilitation Thesis, Technische Universität München, Bavaria, Germany, 1998.

34. Krätschmer, W.; Wagner, B. Molekül-Linien in den Spektren von im Labor produzierten Kohlenstoff-Staubteilchen. In Jahresbericht des Max-Planck-Instituts für Kernphysik Heidelberg 1988; Klapdor, H.V., Jessberger, E.K., Eds.; MPI: Heidelberg, Germany, 1989.

35. Iijima, S. Helical microtubes of graphitic carbon. Nature 1991, 354, 115-122. [CrossRef]

36. Seidel, R.; Duesberg, G.S.; Unger, E.; Graham, A.P.; Liebau, M.; Kreupl, F. Chemical Vapor Deposition Growth of Single-Walled Carbon Nanotubes at $600^{\circ} \mathrm{C}$ and a Simple Growth Model. J. Phys. Chem. B 2004, 108, 1888-1893. [CrossRef]

37. Hata, K.; Futaba, D.N.; Mizuno, K.; Namai, T.; Yumura, M.; Ijima, S.I. Water-Assisted Highly Efficient Synthesis of Impurity-Free Single-Walled Carbon Nanotubes. Science 2004, 306, 1362-1364. [CrossRef]

38. Stehl, C.; Fischer, M.; Gsell, S.; Berdermann, E.; Rahman, M.S.; Traeger, M.; Klein, O.; Schreck, M. Efficiency of dislocation density reduction during heteroepitaxial growth of diamond for detector applications. Appl. Phys. Lett. 2013, 103, 151905. [CrossRef]

39. Melville, A.; Mairoser, T.; Schmehl, A.; Fischer, M.; Gsell, S.; Schreck, M.; Awschalom, D.D.; Heeg, T.; Holländer, B.; Schubert, J.; et al. Epitaxial growth of europium monoxide on diamond. Appl. Phys. Lett. 2013, 103, 222402. [CrossRef]

40. Thomsen, C.; Reich, S. Raman Scattering in Carbon Nanotubes. In Light Scattering in Solid IX; Cardona, M., Merlin, R., Eds.; Springer: Berlin/Heidelberg, Germany, 2007; Volume 108, pp. 115-232. 
41. Ge, C.; Li, Y.; Yin, J.-J.; Liu, Y.; Wang, L.; Zhao, Y.; Chen, C. The contributions of metal impurities and tube structure to the toxicity of carbon nanotube materials. NPG Asia Mater. 2012, 4, e32. [CrossRef]

42. Bachmann, P.K.; Leers, D.; Wiechert, D.U. Diamond Thin Films: Preparation, Characterization and Selected ApplicationsProgress Report. Ber. Bunsenges. Phys. Chem. 1991, 95, 1390-1400. [CrossRef]

43. Spear, K.E. Diamond-Ceramic Coating of the Future. J. Am. Ceram. Soc. 1989 72, 171-191. [CrossRef]

44. Reich, S.; Thomsen, C.; Maultzsch, J. Carbon Nanotubes: Basic Concepts and Physical Properties; Wiley-VCH: Berlin, Germany, 2004.

45. Caccamo, M.T.; Mavilia, G.; Magazù, S. Thermal Investigations on Carbon Nanotubes by Spectroscopic Techniques. Appl. Sci. 2020, 10, 8159. [CrossRef]

46. Rao, A.M.; Richter, E.; Bandow, S.; Chase, B.; Eklund, P.C.; Williams, K.A.; Fang, S.; Subbaswamy, K.R.; Menon, M.; Thess, A.; et al. Diameter-selective Raman scattering from vibrational modes in carbon nanotubes. Science 1997, 275, 187. [CrossRef]

47. Maultzsch, J.; Reich, S.; Thomsen, C. Raman scattering in carbon nanotubes revisited. Phys. Rev. 2002, B65, 233402. [CrossRef]

48. d'Agostino, R. Plasma Deposition, Treatment, and Etching of Polymers; d'Agostino, R., Flamm, D., Auciello, O., Eds.; Academic Press, Inc.: New York, NY, USA, 1990.

49. Möller, W. Plasma and Surface Modeling of the Deposition of Hydrogenated Carbon Films from Low-Pressure Methane Plasmas. Appl. Phys. 1993, A56, 527-546. [CrossRef]

50. Fortin, J.B.; Lu, T.-M. The Growth and Properties of Parylene Thin Films; Springer Science: New York, NY, USA, 2004.

51. Franz, G. Low Pressure Plasmas and Microstructuring Technology; Springer: Berlin/Heidelberg, Germany, 2009; p. 409, for Ta/Si sputtering in oxygen-doped Ar atmospheres.

52. Bayer, C. Aufbringung von Siliziumoxidschichten durch Plasma-CVD und Anwendung auf Beschichtungen in einer PlasmaWirbelschicht. Ph.D. Thesis, ETH, Zurich, Switzerland, 1998.

53. Soll, C. Plasmapolymerisation von Hexamethyldisolxan zur Abscheidung von Quarzähnlichen Schichten bei Gepulster Leistungszufuhr. Ph.D. Thesis, Bergische Universität, Wuppertal, Germany, 2000.

54. Rauf, S.; Kushner, M.J. Controller design issues in the feedback control of radio frequency plasma processing reactors. J. Vac. Sci. Technol. 1999, A17, 704-712. [CrossRef]

55. Kinder, R.L.; Kushner, M.J. Wave propagation and power deposition in magnetically enhanced inductively coupled and helicon plasma sources. J. Vac. Sci. Technol. 2001, A19, 76-86. [CrossRef]

56. Franz, G.; Schamberger, F. Evaporation and thermal cracking of dimeric parylenes. J. Vac. Sci. Technol. 2013, A31, 061602. [CrossRef]

57. Cariou, F.E.; Valley, D.J.; Loeb, W.E. Poly-para-xylylene in thin film application. IEEE Trans. Parts 1965, 1, 54-62. [CrossRef]

58. Beach, W.F. A Model for the Vapor Deposition Polymerization of p-Xylylene. Macromolecules 1978, 11, 72-76. [CrossRef]

59. Fortin, J.B.; Lu, T.-M. A Model for the Chemical Vapor Deposition of Poly para-xylylene Parylene Thin Films. Chem. Mater. 2002, 14, 1945-1949. [CrossRef]

60. Semlyen, J.A. Ring-chain equilibria and their conformations of polymer chains. Adv. Polym. Sci. 1976, 22, 41-75.

61. Reichel, A.; Franz, G.; Amann, M.-C. Correlation of Growth and Surface Properties of Polyp-xylylenes to Reaction Conditions. Coatings 2015, 5, 142-171. [CrossRef]

62. Fortin, J.B.; Lu, T.-M. The Growth and Properties of Parylene Thin Films; Springer Science: New York, NY, USA, 2004 ; Chapter 5.

63. Rogojevic, S.; Moore, J.A.; Gill, W.N. Modeling vapor deposition of low-K polymers: Parylene and polynaphtalene. J. Vac. Sci. Technol. 1999, A17, 266-274. [CrossRef]

64. Yasuda, H.; Chun, B.H.; Cho, D.L.; Lin, T.J.; Yang, D.J.; Antonelli, J.A. Interface-Engineered Parylene C Coating for Corrosion Protection of Cold-Rolled Steel. Corrosion 1996 52, 169. [CrossRef]

65. Blackburn, E.V.; Timmons, C.J. The photocyclisation of stilbene analogues. Quart. Rev. 1969, 23, 482. [CrossRef]

66. Olson, R. Xylylene Polymers. In Encyclopedia of Polymer Science and Engineering, 2nd ed.; Wiley: Hoboken, NJ, USA, 1989; Volume 17, pp. 990-1024.

67. Streitwieser, A., Jr.; Ward, H.R. Organic Compounds in Microwave Discharges. II. Initial Sudies with Toluene and Related Hydrocarbons. J. Am. Chem. Soc. 1963, 85, 539-542. [CrossRef]

68. Stahl, U. Entwicklung eines Verfahrens zur Stabilisierung von Polymerschichten auf OFW-Sensoren für die Analytik von organischen Gasen. Ph.D. Thesis, TU Karlsruhe, Karlsruhe, Germany, 1999.

69. Wertheimer, M.R.; Moisan, M. Comparison of Microwave and Lower Frequency Plasmas for Thin Film Deposition and Etching. J. Vac. Sci. Technol. 1985, A3, 2643-2649. [CrossRef]

70. Moisan, M.; Barbeau, C.; Claude, R.; Ferreira, C.M.; Margot, J.; Paraszczak, J.; Sá, A.B.; Sauvé, G.; Wertheimer, M.R. Radio frequency or microwave plasma reactors? Factors determining the optimum frequency of operation. J. Vac. Sci. Technol. 1991, B9, 8-25. [CrossRef]

71. Kaelble, D.H. Physical Chemistry of Adhesion; John Wiley: New York, NY, USA, 1971.

72. Wenzel, R.N. Resistance of solid surfaces to wetting by water. Ind. Eng. Chem. 1936, 28, 988-994. [CrossRef]

73. Cassie, A.B.D.; Baxter, S. Wettability of porous surfaces. Trans. Faraday Soc. 1944, 40, 546-550. [CrossRef]

74. Hwang, K.S.; Park, J.H.; Lee, J.H.; Yoon, D.S.; Kim, T.S.; Han, I.; Noh, J.H. Effect of Atmospheric-Plasma Treatment for Enhancing Adhesion of Au on Parylene-C-Coated Protein Chips. J. Korean Phys. Soc. 2004, 44, 1168-1172.

75. Senkevich, J.J.; Mitchell, C.J.; Vijayaraghavan, A.; Barnat, E.V.; McDonald, J.F. Unique structure/properties of chemical vapor depositied parylene E. J. Vac. Sci. Technol. 2002, A20, 1445. [CrossRef] 
76. Shin, Y.S.; Cho, K.; Lim, S.H.; Chung, S.; Park, S.-J.; Chung, C.; Han, D.-C.; Chang, J.K. PDMS-based micro PRC chip with Parylene coating. J. Micromech. Microeng. 2003, 13, 768-774. [CrossRef]

77. Pruden, K.G.; Sinclair, K.; Beaudoin, S. Characterization of Parylene-N and Parylene-C Photooxidation. J. Polym. Sci. Part A Polym. Chem. 2003, 41, 1486-1496. [CrossRef]

78. Zhuang, Y.X.; Menon, A. Wettability and thermal stability of fluorocarbon films deposited by deep reactive ion etching. J. Vac. Sci. Technol. 2005, A23, 434-439. [CrossRef]

79. Liston, E.M.; Martinu, L.; Wertheimer, M.R. Plasma surface modification of polymers for improved adhesion: A critical review. J. Adhes. Sci. Technol. 1993, 7, 1091-1127. [CrossRef]

80. Liston, E.M. Plasma treatment for Improved Bonding: A Review. J. Adhes. 1989, 30, 199-218. [CrossRef]

81. Bi, X.; Crum, B.P.; Li, W. Super Hydrophobic Parylene-C Produced by Consecutive $\mathrm{O}_{2}$ and SF 6 Plasma Treatment. J. Microelectromech. Syst. 2014, 23, 628-635. [CrossRef]

82. Tsougeni, K.; Petrou, P.S.; Tserepi, A.; Kakabakos, S.E.; Gogolides, E. Nano-texturing of polymethyl metacrylate polymer using plasma processes and applications in wetting control and protein absorption. Microelectron. Eng. 2009, 86, 1424-1427. [CrossRef]

83. Zare, H.H.; Düttmann, O.; Vass, A.; Franz, G.; Jocham, D. Silver ions eluted from partially protected silver nanoparticles. Biointerphases 2016, 11, 031002. [CrossRef] [PubMed]

84. Zare, H.H.; Juhart, V.; Vass, A.; Franz, G.; Jocham, D. Efficacy of silver/hydrophilic polyp-xylylene on preventing bacterial growth and biofilm formation in urinary catheters. Biointerphases 2017, 12, 011001. [CrossRef]

85. Franz, G.; Schamberger, F.; Zare, H.H.; Bröskamp, S.F.; Jocham, D. Bi-layer sandwich film for antibacterial catheters. Beilstein J. Nanotechnol. 2017, 8, 1982. [CrossRef] [PubMed]

86. Tserepi, A.D.; Vlachopoulou, M.-E.; Gogolides, E. Nanotexturing of polydimethylsiloxane in plasmas for creating robust super-hydrophobic surfaces. Nanotechnology 2006, 17, 3977-3983. [CrossRef]

87. Kokkoris, G.; Constantoudis, V.; Angelikopoulos, P.; Boulousis, G.; Gogolides, E. Dual nanoscale roughness on plasma-etched Si-surfaces: Role of etch inhibitors. Phys. Rev. 2007, B76, 193405-193408. [CrossRef]

88. Kim, J.; Choi, S.-O. Superhydrophobicity. In Waterproof and Water Repellent Textiles and Clothing; The Textile Institute Book Series; Elsevier: Amsterdam, The Netherlands, 2018; pp. 267-297.

89. Rioboo, R.; Demnati, I.; Ali, M.A.; Sevkan, R.; de Coninck, J. Superhydrophobicity of composite surfaces created from polymer blends. J. Coll. Interf. Sci. 2020, 560, 596-605. [CrossRef] 